(Aus der Universitäts-Augenklinik Basel.)

\title{
Weitere Ergebnisse der Spaltlampenmikroskopie des vorderen Bulbusabschnittes.
}

\author{
III. Abschnitt. \\ Angeborene und früh erworbene linsenveränderungen. \\ Von \\ Prof. Dr. Alfred Vogt, \\ vorsteher der Klinik.
}

Nit 36 Textabbildungen.

Die pathologische Anatomie hat auf dem Gebiete der Kataraktgenese, vor allem des Altersstars, im letzten Jahrzehnt kaum Neues zutage gefördert. - Der Grund hierfür liegt nicht etwa darin, daB die Pathologie des Stars erschöpft ist, im Gegenteil, die anatomische Untersuchung hat uns über wichtigste Fragen, z. B. den Aufbau der verschiedenen Altersstartypen, dio Art und Weise ibres Beginns, Verlaufs und Ausgangs entweder gar keinen, oder nur mangelhatten AufschluB gegeben. Die Ursache hierfür bilden vielmehr hauptsächlich die außergewöhnlichen technischen Schwierigkeiten, welche der Verarbeitung, besonders seniler Linsen, entgegenstehen.

Einmal eignet sich zur anatomischen Untersuchung nur ganz frisches, und daher schwer erhältliches Linsenmaterial. Vakuolenbildungen, Flüssigkeitsansammlungen in den Nähten und unter der Kapsel, Faserveränderungen treten schon kurze Zeit post mortem auf, so rasch, daß ursprünglich derartige Leichenerscheinungen für normal gehalten wurden. Wer die anatomischen Bilder der siebziger und achtziger Jahre des vorigen Jahrhunderts durchgeht, wird sich oft von solchen postmortalen Veränderungen überzeugen.

Dann aber bekommen die Linsen älterer Personen durch die Fixierung und Härtung eine derartige homige bis steinharte Konsistenz, daß sie, wenn wir etwa von den Rindenpartien absehen, mikrotomisch nicht verarbeitbar sind.

In der Rinde zerstört ferner der Konservierungsprozeß einen Teil jener Veränderungen, welche das klinische Bild des Altersstars ausmachen. Vor allem sind es die Myelintröpfehen, aus welchen ja die Hauptmasse der trüben Partien besteht, die zur unförmlichen Masse 
zusammenschrumpfen, wodurch die Struktur der Trübung verloren geht. Auch Flüssigkeitsschichten, wie die sog. Wasserspalten, welche Fasern und Nähte auseinanderdrängen, sind trotz ihrer großen Häufigkeit und des sehr auffälligen Bildes, das sie hervorrufen, anatomisch (außer an der frischen unpräparierten Leichenlinse) noch nicht beobachtet oder irgendwie nachgewiesen worden. Es stellen aber gerade diese Spalten ein hauptsächliches Symptom des Alterstars dar.

Was die Fasern und ihre Veränderungen anbelangt, so zeigten mir vergleichende Untersuchungen, daß zu ihrer Darstellung noch am ehesten die Rablsche Sublimatplatinchlorid-Methode geeignet ist, vorausgesetzt, daß die Linse in situ fixiert werden kann.

Doch wird man auch bei dieser Methode mit der Deutung von "Quellung“", ,Verbiegung" usw. von Fasern gerade der menschlichen Linse vorsichtig sein müssen, bat doch schon Rabl auf die Mannigfaltigkeit der Morphologie gerade des menschlichen Linsenfaserquerschnitts hingewiesen. Wir selber haben seine Befunde bestätigt und erweitert (vgl. die Abb. 101 und 102 in unserem Atlas der Spaltlampenmikroskopie).

Gegenüber der anatomischen Untersuchung tritt die klinische seit Schaffung der Spaltlampenmikroskopie ganz besonders in den Vordergrund. - Gullstrand war es bald nach Erfindung der Spaltlampe gelungen, innerhalb der Linse eine vordere und eine hintere Diskontinuitätsfläche, auf die er die sog. Kernbildchen bezog, festzustellen. (A. Gullstrand, Einführung in die Methoden der Dioptrik des Auges des Menschen, 1911, S. 21.) Nach der Beschreibung dürfte das hintere der beiden von ihm beobachteten Maxima der hinteren Embryonalkernfläche entsprechen (,der Abstand dieses zweiten Maximums von der hinteren Linsenfläche ist scheinbar das Doppelte bis Dreifache des Abstandes des ersten Maximums von der vorderen").

Eine Reihe von Verbesserungen haben die Leistungsfähigkeit der neuen Methode ganz wesentlich erhöht. So die Kombination der Spaltlampe mit dem Binocularmikroskop (Henker), die Steigerung der spezifischen Helligkeit der Lichtquelle durch Anwendung von Nitraund Mikrobogenlampe, die Verfeinerung des Büschels (Lochbüschel und verschmälertes Büschel) und die Benützung des Prinzips der Spiegelbezirke optischer Grenzflächen, durch welche Verbesserungen neue physiologische Befunde an der Linse aufgedeckt wurden. Es seien hier nur die typischen Diskontinuitätsflächen (Abspaltungsflächen, Alterskern- und Embryonalkernflächen), die Reliefbildung der Alterskernoberfläche, die Nahtsysteme und das zentrale Intervall, die physiologischen embryonalen Reste der vorderen und hinteren Iinsenflacche hervorgehoben. Die vordere und hintere Linsenoberfläche, die vor der Zeit der Spaltlampe n u r indirekt, durch ihre Spiegelbilder nachgewiesen 
werden konnten, werden zu diffus reflektierenden, scharf begrenzten Flächen. Ein Streit über die Lage von Linsenveränderungen (z. B. Trübungen, Vakuolen. Wasserspalten) in bezug auf diese Flächen ist keute nicht mekr möglich.

Das Linseninnere, das bisher klinisch als homogen gelten mußte. Lat nicht nur eine Topographie gefunden, sondern die erwähnten Verfeinerungen der Metlodik gestatten eine unmittelbare und genace Tiefenlokalisation.

Die Beherrschung der Technik setzt allerdings gerade bei der Linsenuntersuchung eine nicht zu unterschätzende Ubung voraus. Nur fortgesetzte tägliche Handhabung in "der Fokussierung des Büschels und in der gleichzeitigen Tiefeneinstellung des Mikroskops auf "das niemals völlig fixe Objekt bringen jene Fertigkeit, welche das Spaltlampenmikroskop zu einem bequem und rasch arbeitenden Instrument wacht.

Daß die Gullstrandscle Erfindung für diejenigen, die thr Prinzip überseken, zum Verhängnis werden kann, Laben gerade auf dem Gebiete der Linsenforschung verschiedene Mitteilungen der letzten Jahre dargetan.

Den nachfolgenden Beobachtungen an der Linse, welche als Fortsetzung meiner Mitteilungen im Atlas der Spaltlampenmikroskopie zu denken sind, seien einige allgemeine physiologische Bemerkungen vorausgeschickt.

Was zunächst die Konstanz der Diskontinuitätsflächen betrift, so hat das verschmälerte Nitra- und Bogenlampenbüschel das regelmäßige Vorkommen der sog. Abspaltungsfläche (Verf., Ber. O. G. Heidelterg 1918) sowohl in der vorderen als in der hinteren Rinde ergeben. Es bestätigte sich auch unsere frühere Feststellung (S.60 des Atlas der Spaltlampenmikroskopie), daß diese Fläche niemals, wie man bei ungenauer Einstellung in einzelnen Fällen annekmen könnte, in den axialen Partien mit der Kapselzone in Kontinuität steht; noch deutlicher als mit Nernstlicht ließ sich mit der neuen Metrode ein lucides Intervall zwischen beiden Flächen nachweisen.

Wenn wir im folgenden, wie bisher, von ,Alterskern" und ,Alterskerntläche" sprechen, so ist darunter die in der Regel auf die Abspaltungsfläche folgende, zweite kräftige Diskontinuitätszone verstanden. Während deren Unterscheidung von anderen Zonen i m Alter gewöhnlich keine Schwierigkciten bietet - sie unterscheidet sich von jenen durch ihre Lichtstärke, ihre Lage zwischen Linsenoberfläche und vorderer Embryonalnaht (ersterer etwas näher gerückt), ihre senile Reliefbildung - so kann die Entscheidung in seltenen (meist pathologischen) Fällen schwieriger sein, sofern nämlich mehrere Flächen zwischen Embryonalkern und Kapsel nachweisbar sind. Wir werden unter diesen Flächen die lichtstärkste als Alterkernokerfläche auffassen. 
Auch bei Kindern bezeichnen wir die auf die Abspaltungsfläche folgende Zone als "Alterskernfläche", trotzdem noch nicht nachgewiesen ist, daß diese bei Kindern nicht immer gleich deutlich nachweisbare Zone identisch ist mit der "Alterskernzone" des Erwachsenen ${ }^{1}$ ). Systematische Untersuchungen an großem Material werden hier wohl Aufklärung bringen. Einstweilen sind wir berechtigt, auch bei Kindern von "Alterskernzone" zu sprechen, indem bis jetzt keine Tatsachen vorliegen, die einer derartigen Auffassung widersprechen.

Was die Beobachtung des vorderen Oberflächennahtsystems betrifft, so haben uns fortgesetzte vergleichende Untersuchungen die außerordentliche individuelle Verschiedenheit in der Deutlichkeit desselben am normalen Auge ergeben. Jugendliche Individuen zeigen häufig das System in jeder nur wünschenswerten Schärfe, und zwar vornehmlich bei Einstellung der Chagrinierung. Doch sind die Fälle nicht so selten, wo auch ohne die letztere die oberflächliche Nahtfigur deutlich zutage tritt.

Schon im Atlas der Spaltlampenmikroskopie wurde S. 57, Abb. 92b, erwähnt, daß die Chagrinierung unter Umständen mit Nahtlinien scharf abschneidet. Die Chagringrenze fällt also in solchen Fällen mit einer Nahtlinie zusammen. Es werden dadureh Nahtfirsten der Linsenvorderfläche vorgetäuseht, die etwa an die Firsten eines Regenschirmdaches gemahnen. Die Erklärung für diese Erscheinung ist wohl folgende: An der Chagrinierung beteiligen sich nicht nur Kapsel und Epithelien, sondern, wie die Naht- und Faserzeichnung beweisen, auch die Faseroberfläche. Die Fasern zu beiden Seiten einer Naht weisen aber eine symmetrische Anordnung auf, woraus folgt, daß bei Belichtung von einer Seite her die Reflexion der beiden symmetrischen Nahtpartien für das Beobachterauge nicht eine identische ist. Die Naht bildet die Grenzlinie dieses differenten optischen Verhaltens und wird daher unter Umständen als Reflexionsgrenzlinie zutage treten müssen. Daß diese Erklärung zutrifft, geht daraus hervor, daß in den hierauf untersuchten Fällen der an die Nahtlinie grenzende Spiegelbezirk nicht nur relativ lichtschwach ist, sondern auch besonders deutliche Faserzeichnung erkennen läßt.

Der Umstand, daß sowohl Kapseldicke als Epithelhöhe zwischen Pol und Äquator stetig sich ändern, muß zur Folge haben, daß der aus verschiedenen Komponenten resultierende Chagrin in seinen verschiedenen Abschnitten eine verschiedene Zusammensetzung hat. In der Tat ist die Zeichnung des vorderen Linsenspiegelbezirks von der Einfalls- und Beobachterrichtung abhängig. So zeigen die lichtschwä-

1) Der Nachweis dieser Fläche gelingt am leichtesten, wenn wir uns in der Hauptausfallsrichtung des von der Zone reflektierten Lichtes befinden (vergl. Verf. 5. 56 der Atlas der Spaltlampenmikroskopie). 
cheren Randpartien unter Umständen Faserzeichnung, wo eine solche in den übrigen Bezirken fehlt. Für das Sichtbarwerden der obenerwähnten scheinbaren Firstbildung müssen aber naturgemäß dann die günstigsten Bedingungen vorhanden sein, wenn das gespiegelte Licht mehrheitlich von der Faseroberfläche stammt.

In bezug auf die von mir im Atlas der Spaltlampenmikroskopie S. 66 und früher (Arch. f. Ophthalmol. 88, 329. 1914) erörterten Beziehungen zwischen Faserbreite und Nahtiänge, ist in geschichtlicher Hinsicht nachzutragen, daß schon Kölliker (Mikroskopische Anatomie des Menschen, Leipzig 1852, S. 710) sich mit diesem Gegenstand durch folgende Bemerkung befaßt hatte: „Allein an den Endigungen finde ich die Fasern fast obne Ausnahme verbreitert, was auch gar nicht anders sein kann, wenn man bedenkt, wie zahlreich und lang die Strahlen der Linsensterne sind, an welchen die Fasem sich ansetzen."

Schon Kölliker hatte also offenbar erkannt, daß die terminale Verbreiterung der Linsenfasern vom Nabtsysteme abhängt. Babuchin (Strickers Handbuch der Lehre von den Geweben II, S. 1087. 1871) äußert sich in ähnlicher Weise.

Die Wichtigkeit eines eingehenderen Studiums der Nahtsysteme einerseits, der Linsen masse verschiedener, besonders fötaler Lebensabschnitte andererseits, geht, hoffe ich, aus den nachstehenden Beobachtungen hervor. Sie zeigen uns, daB hier ein Weg offensteht, der neue Anhaltspunkte für đie bisher gänzlich unabgekJärte zeitliche Genese jugendlicher oder angeborener Katarakte bringen kann und dadurch vielleicht einzelnen Hypothesen Schranken setzt.

Bei manchen Ophthalmologen ist heute noch der Ausdruck ,,vorderer und hinterer Sternstrahl" üblich, worunter offenbar das Nahtsystem verstanden ist. Dem Ausdruck liegt die irrige ursprüngliche Auffassung zugrunde, daß die Nähte der menschlichen Linse axial in einem Punkte sich treffen (vgl. z. B. Babuchin, I. c. S. 1085). Genauer ist es, statt von ,Sternstrahlen", von Nähten und Nahtsystemen zu sprecken.

Der radiäre Verlauf der Nähte macht sich bei seitlicher Beleuchtung der meisten Linsen mehr oder weniger deutlich durch helle, unscharfe, ziemlich breite Radiärstreifen bemerkbar, welche oft eine lebhaft weiRe Sternfigur vortäuschen, deren Strahlen allerdings bei Änderung von Einfalis- und Beobachterrichtung etwas wandern. Bei einer Reihe von Personen babe ich mich am Spaltlampenmikroskop überzeugt, daß die hellen Streifen durch die Reflexion der Endabschnitte der Fasern bedingt sind, welche Reflexion im Alter eine lebhaftere wird. Da nun die Nahtflächen mehr oder weniger senkrecht zur Äquatorialebene stehen, so wird auch die erwähnte scheinbare Wanderung verständlich (vgl. Atlas der Spaltlampenmikroskopie S. 63). 
In bezug auf die Darstellung von Linsentrübungen, auch solcher feinster Art, ist durch die Steigerung der spezifischen Helligkeit (Nitraund Mikrobogenlampe) ein weiterer Fortschritt erzielt worden. Es treten Punkt- und Staubtrübungen zutage, die im Nernstlichte noch nicht sichtbar waren. So fand ich z. B. im Laufe der letzten zwei Jahre im ganzen bei etwa 20 Augen eine feine, weiße bis bräunliche, dichte Punktierung der vorderen oberfächlichen Rindennähte, welche ich als vordere axiale Rindennahtpunktierung bezeichne und welche die axialen Partien des vorderen Rindennahtsystems in zierlicher Zeichnung hervortreten läßt. Uber diese anscheinend jahrelang ziemlich stationär bleibende Nahtpunktierung wird im Kapitel „Altersveränderungen "i genauer berichtet.

Was endlich die Genese der Linsentrübungen betrifft, so können wir auch in der Ophthalmologie an den gewaltigen Frrungensehaften der experimentellen Vererbungsforschung nicht achtlos vorübergehen. - Gerade auf dem Gebiete der angeborenen oder früh aufgetretenen vererbbaren Starformen werden mechanistische Anschauungen (von chemisch-nutritiven Noxen, mechanischen Entwicklungsstörungen) künftig unter dem Gesichtspunkte der neugewomnenen Erfahrungen beurteilt werden müssen. Allerdings sollen uns diese letzteren nicht abhalten, auch weiterhin nach exogenen Ursachen zu forschen, wo solche in Betracht kommen können. Wo aber die Heredität und damit die Anlage im Keimplasma nachgewiesen ist, können derartige Erklärungen nicht oder nur bedingt befriedigen. Die ältere medizinische Denkweise verschließt sich auch heute noch zum Teil der Einsicht, daß eine bestimmte Zellgruppe zu bestimmter Lebenszeit, ohne irgendwelche erkennbare äußere Ursache, bei völlig normalen Verhältnissen der Umgebung der Degeneration verfallen kann. Aber an der Tatsache ist nicht mehr zu zweifeln. Oder ist es nicht ein selbständiges; nur durch die idioplasmatische Anlage gegebenes Merkmal, wenn bei Lebers̉eher Krankheit in einem bestimmten Alter, gewöhnlich im dritten Jahrzehnt, bei durchschnittlich der Hälfte der männlichen Individuen einer Sippschaft ein bestimmer Abschnitt des Opticus, das papillomaculäre Bündel die Funktion einstellt und zerfallt, und zwar bei normalem Verhalten des Gesamtorganismus?

Hier prinzipiell als atiologisches Moment s ta t u n mittelbarer Verexb ung eine exogene Noxe verantwortlich zu machen, wäre gleichbedeutend mit einer Zurückführung homochroner Vererbung auf äußere (paratypische, i.e. nicht durcli die Erbanlage bedingte) Einflüsse, oder gleichbedeutend mit einerV ers chiebung, aber nicht Er klär ung der Ursache. Abgesehen davon, daß eine derartige Hypothese nicht gestützt wäre und mit den tatsächlichen Erfahrungen überVererbung in Widerspruch stände, würden wir mit einer solchen grundsätzlichen Auffassung dasProblem, statt 
es zu fördern, weiter komplizieren. Nicht mehr die Merkmale als solche wären dann vererbt, in unserem Beispiele also nicht mehr die Degeneration des papillomaculären Bündels, sondern ein - unbekanntes! vielleicht endokrines Organ müBte primär erkrankt sein, wobei ihm gerade die Eigenschaft zukäme, das papillomaculäre Bündel - und nur dieses - zu schädigen. In ähnlicher Weise würden auch für die anderen zahllosen Merkmale homochroner Vererbung ganz spezifische Noxen als Ursachen zu supponieren sein, so daß wir zu unmöglichen Forderungen gelangen würden.

Aber es darf trotzdem nicht übersehen werden, daß vereinzelt eine direkte Vererbung vorgetäuscht wird. Erinnern wir uns z. B., daß Augen mit Mikrocornea vererbt werden, daß aber bei solchen relativ oft Glaukom auftritt. Fs ist in diesem Fall sehr wahrscheinlich, daß die Mikrocornea der Ausdruck einer besonderen Bulbusstruktur ist, die im höheren Alter Glaukom auslöst. Das letztere ist somit Folgeerscheinung des vererbten Merkmals. Oder: Frühzeitige schwere Linsenschädigung kann, wie das auch Experimente wahrscheinlich machen, Mikrophthalmus zur Folge haben (vgl. z. B. den Fall unserer Abb. 28). Die Linsenschädigung ist also das primäre (evtl, vererbte) Merkmal, der Mikrophthalmus eine Folgeerscheinung.

Nach derartigen Beziehungen ist somit bei der Beurteilung aller vererbten Merkmale zu fahnden, und es sind anch in der nachfolgenden Darstellung angeborener oder frühzeitiger Stare jene Faktoren kurz berücksichtigt worden, welche bei der Entstehung unter Umständen von Bedeutung sein könnten. Dabei erheben wir keineswegs den Anspruch, alle in Betracht kommenden Möglichkeiten erschöpft zu haben.

Im AnschluB an die Darstellung in meinem Atlas der Spaltlampenmikroskopie sollen im folgenden weitere Beobachtungen über Linsentrübungen kongenitaler oder früh aufgetretener Art mitgeteilt werden. Wo bei den Bildern nichts Besonderes vermerkt ist, geschah die Beobachtung bei 24-25facher LinearvergröBerung1) (Oc. 2, Obj, a 2). In zwei späteren Kapiteln werden Beobachtungen über Cataracta senilis und complicata folgen.

\section{Congenitale Linsenveränderungen.}

Ungewöhnlicher Typus der kongenitalen Sternchenauflagerungen auf der Vorderkapsel (Abb. $1 \mathrm{a}, \mathrm{b})$.

Die Sternchenform des angeborenen Vorderkapselpigments hat anscheinend als erster Brückner in seiner Arbeit über die Reste der Tunica vasculosa lentis (Arch. f. Augenheilk. 1907, Erg.-Bd. S. 84) beschrieben. Er sah damals nur Sternchen von höchstens 3-4 Strahlen.

1) Durch die Reproduktion fand durchsohnittlich eine Verkleinerung um $1 / 4$ statt. 
Später haben Stähli, Kraupa, Koeppe und andere eine geformte Natur des Pigments ebenfalls erkannt, ohne auf die früheren Beobachter bezug zu nehmen ${ }^{1}$ ). Als unzutreffend hat sich mir die von Brückner gemachte Annahme erwiesen (1.c. S. 60), daß angeborenes Pigment sich morphologisch von erworbenem sicher trennen lasse. Wie ich durch jahrelange Beobachtung feststellen konnte, nimmt auch erworbenes Pigment der Vorderkapsel häufig im Laufe von Monaten und Jahren Sternchenform an. Umgekehrt kann angeborenes Pigment in seltenen Fällen amorph bleiben (vgl. die Abb. 141-145 meines Atlas der Spaltlampenmikroskopie). Kra u pa (Arch.

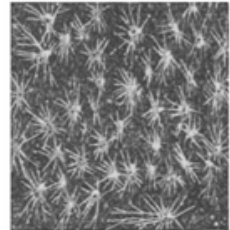

Abb. 1 a. f. Augenheilk. 1917) nennt das angeborene Vorderkapselpigment ,, kommaförmig", und hat bereits beobachtet, daß auch erworbenes Pigment regelmäßige Form gewinnen kann.

Häufig sind die angeborenen Pigmentsternchen der Vorderkapsel nicht nur drei- und vier-, sondern auch vielstrablig. Daß aber das Pigment die Gestalt der Sternchen unserer $\mathrm{Abb}$. $\mathrm{l} a$ und $\mathrm{b}$ annimmt, gehört zu den großen Seltenheiten. Durch die zahlreichen Strahlenfäden in diesem Falle bekommen die Sternchen Stechapfelform. Ich sah diesen Typus unter vielen hunderten von Beobachtungen nur dies eine Mal (linkes Auge des bis

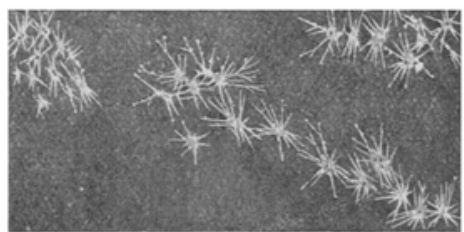

Abb. 1 b. jetzt nie augenkranken 12 jährigen $H . H ., 51$ fache Linearvergrößerung; der Kern der Sternchen ist bräunlich, die Strahlenfäden sind grauweiB).

Die Farbe der angeborenen Pigmentsternchen steht ganz allgemein in Beziehung zur Farbe der Iris. Ist letztere blau oder grau, so sind die Sternchen häufig grau bis grauweiß. Bei brauner Iris sind sie fast ausnahmslos braun. Bei erworbenem Pigment (nach Entzündungen) sind die Ausläufer gelegentlich weiß, die Mittelpunkte braun.

\section{Weiße und braune Pupillarfadenkörperchen und mesodermale Pigmentgenese.}

Die auf den spinnwebartig durchscheinenden, farblosen, die Vorderkammer manchmal gleich Telegraphendrähten durchziehenden $\mathrm{Pu}$ pillarfäden häufig aufsitzenden grauen oder braunen Klümpchen (Atlas der Spaltlampenmikroskopie, z. B. Abb. 142) sind vielleicht den von

1) Gute Abbildungen dieses gewöhnlichen Sternchenpigmentes bringt auch eine neueste Mitteilung von Rumbaur (Klin. Monatsbl. f. Augenheilk. 66, 737. 1921. 
uns beschriebenen "Hyaloideakörperchen“ analog zu setzen (Verf., Arch. f. Ophthalmol. 100, 328, und Atlas der Spaltlampenmikroskopie $A b b .156,159,163)$. Diese Pupillarfädenkörperchen fand ich bei brauner Iris meist braun, bei blauer oder grauer dagegen farblos (gelegentlich kommen bei brauner Iris neben braunen gleichzeitig farblose Klümpchen vor). Sie zeigen also ein ähnliches Verhalten wie die oben erwähnten Sternchenauflagerungen der Vorderkapsel. Schon Brüekner (1. c. S. 135) weist, was die embryonalen Pigmentreste auf der Vorderkapsel betrifft, auf diese Tatsache hin und zieht in bezug auf die postfötale Bildung des Pigments den Schluß, daß den Elementen der Reste die Fähigkeit mitgegeben sein müsse, aus sich heraus nur mit Benützung der im Kammerwasser vorhandenen Stoffe die Pigmentbildung in vorher bestimmter Weise vorzunehmen.

Wir schließen uns dieser Auffassung auch in bezug auf die erwäbnten Pupillarfadenkörperchen an. Ganz allgemein sind im Hinblick auf die immer noch strittige autochthone Genese mesodermalen Pigmentes derartige Befunde interessant. Zur Zeit der Geburt pigmentlose, abgesprengte Zellkonglomerate mesodermalen Ursprungs, denen jeder Kontakt mit den Pigmentzellen der Iris verlorenging, pigmentieren sich in der Vorderkammer selbständig. Sie liefern wohl den Beweis, daß Pigment im Mesoderm entstehen kann und daß das Irispigment des Vorderblattes keineswegs ektodermalen Crsprungs zu sein braucht.

\section{Pupillarfäden an vorderen Pyramidalstaren (Abb. 2, 3, 3a-d.).}

An vorderen Polstaren nicht perforativen Ursprungs, bei denen also Zeichen überstandener Keratitis fehlen, sah bisher Horner (Zehenders Monatsbl. 1866, \&. 260; vgl. auch dort eine Bemerkung Zehenders über eine eigene und eine englische Beobachtung) in einem Falle drei Pupillarfäden, Einen ähnlichen Fall teilt ferner Terrien mit (Arch. d'ophthalmol. 34, 230. 1914). Die Spaltlampe lehrt, daß solche Fälle

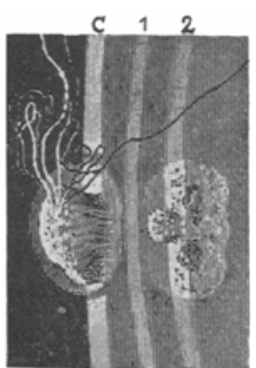

Abb. 2 . nicht so sehr selten sind. Ich gebe die Bilder von vier derartigen Beobachtungen wieder.

1. Bei dem 14 jährigen, bis jetzt nie augenkranken Knaben Soh. besteht rechts die in Abb. 2 gezeichnete vor. dere "Pyramidalkatarakt". Die in die Vorderkammer ragende Prominenz sieht in diesem Falle mehr wie ein ungleichmäßig dicker Zapfen als wie eine Pyramide aus. Auf der Kuppe sitzen neun gewöhnliche Pupillarfäden, die zusammengekräuselt frei schweben, mit Ausnahme von zweien, zur Iriskrause ziehenden. Diese beiden Fäden, ein oberer und ein temporaler, gabeln sich, bevor sie an der Krause inserieren (in der Abbildung nicht mehr $z a$ sehen). Als wir den Knaben vor Jahresfrist zum erstenmal untersuchten, bestand noch ein dritter sehr feiner derartiger Faden, der nun zerrissen ist, so da $\$$ heute dessen an der Katarakt haftendes Ende ebenfalls frei schwebt. 
Die Pyramidalkatarakt, von der noch weiter unten die Rede sein wird, besitzt einen ,Abklatsch" (s. u.) in einer tieferen Diskontinuitätszone (Abb. 2). Von letzterer ist sie durch die Abspaltungszone getrennt. Bemerkenswerterweise zeigt auch dieser "Abllatsch" einen feinen, nach vorn gerichteten Trübungszapfen. $C=$ Vorderkapsel, $1=$ erster, $2=$ zweiter vorderer Diskontinuitätsstreifen. Der Abspaltungsstreifen ist nioht gezeichnet. Der "Abklatsch“" weist auf die frühe Entstehung der Katarakt hin (s. u.).

2. Bei dem 29 jährigen, nie augenkranken Herrn St. zeigt das linke Auge die (1/2 $\mathrm{mm}$ messende) Pyramidalkatarakt der Abbildung 3 bei Chagrineinstellung. Auf der in die Vorderkammer ein wenig prominierenden Kuppe des Stars haftet ein nach oben ziehender $1 \% / 2 \mathrm{~mm}$ langer, frei endigender Pupillarfaden, indem er mit drei Zweigen aus der Katarakt entspringt. Nach rückwärts eine spindelförmig eingeengte Fortsetzung des Stars zur vorderenAlterskernzone, dahinter ein Schatten. In Abbildung 3 beachte man die chagrinfreie dunkle Zone rings um den Star, in Abbildung 3a den Aufbau aus frontal gelagerten konzentrischen Schichten. In dem letzteren Bilde (Ansicht von vorn) ist ein peripherer Grenzring zu sehen, der in Abb. 3

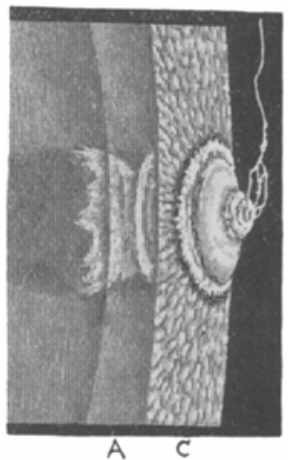

Abb. unter dem Chagrin verschwindet. $C=$ Chagrinstreifen, $A=$ Alterskernstreifen, breites Büschel.

3. Abb. $3 \mathrm{~b}$ stellt den vorderen Polstar des linken Auges eines 12 jährigen Jungen P. M. dar. Von der Spitze der Pyramide zieht ein Faden zur oberen Krause. $C=$ Vorderkapsel, $\mathrm{K}=$ Alterskernstreifen, der den , Abklatsch" enthält. In Abbildung $3 \mathrm{e} 3$ Pigmentsternchen desselben Falles, die sich nasal anreihen.

In Abbildung $3 \mathrm{~d}$ ( 30 jährige H. L.) sitzt im oberen Teil des Stars der gegabelte abgerissene Rest eines

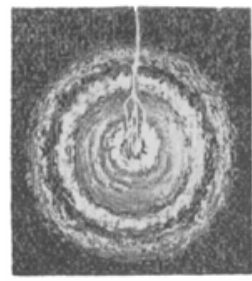

Ablo. 3 a.

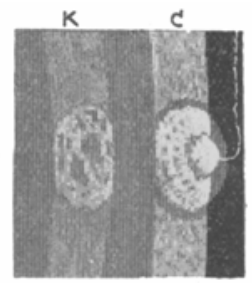

$A b b, 3 \mathrm{~b}$

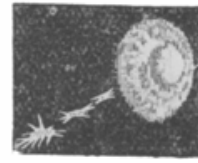

Abb. $:$ e.

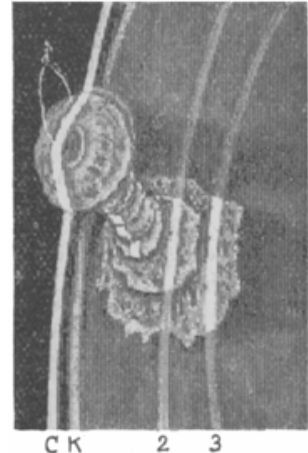

Ab). 3 仿.

Fadens. $C=$ Kapsel, $K=$ Abspaltungsstreifen, 2 und $3=$ zweiter und dritter Diskontinuitätsstreifen. Der spindelförmige, die ganze vordere Rinde und die vorderste Kernpartie durchsetzende Star läßt mehrere Etagen erkennen (schmales Büschel). Über weitere derartige Beobachtungen vergleiche den unten mitgeteilten Stammbaum von vorderer Polkatarakt.

Die Adhärenzen der Pupillarfäden beweisen, daß der vordere Polstar ante partum, und zwar zu einer Zeit entstand, da die Pupillarmembran noch wohl ausgebildet war. Auf welchen genauen Abschnitt des Fötallebens jedoch diese Polstare zu datieren sind, vermögen die 
bisherigen Beobachtungen noch nicht zu entscheiden. Die Adhärenzen der Pupillarmembran machen es immerhin wahrsoheinlich, daß die Katarakt erst nach der Entwicklung der GefäBmembran und somit erst n a ch Abschnürung des Linsenbläschens, also erst nach dem zweiten Fötalmonat zustande kam, so dab eine Störung in der Abschnürung, wie sie für diese und andere Kongenitalstarformen vermutet wird (C. v. Hess), als Ursache nicht wohl anzunehmen ist (s. unten).

\section{Exsudatähnliche (fötale) Membranreste mit verstreuten Kapselstarflecken} $(\mathrm{Abb}, 4)$.

Abb. 4 (schwache Vergrößerung) stellt das typische Bild dieser merkwürdigen, von verschiedenen Autoren, z. B. in nenerer Zeit von Brüek -

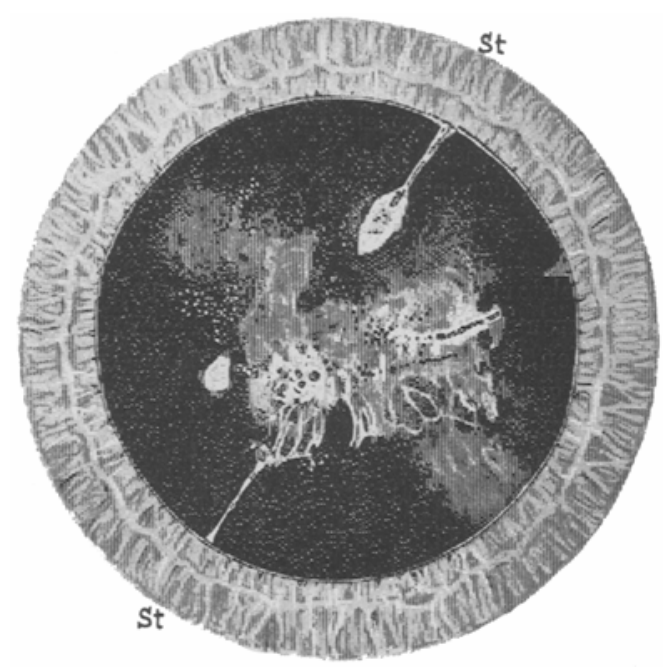

Abb. 4. ner (1.c.), Peters (1909) u. a. gut abgebildeten Gewebsreste aus fötaler Zeit dar. Es ist dieser Typus schon mehrfach auf Entzündung bezogen worden. Auffällig and vom gewöhnlichen Habitus der Membranreste abweichend, sind die derben Stränge $S t$, die bemerkenswerterweise nicht zur Krause, sondern zum Pupillenrand ziehen. Ferner das oft nachweishare graue, exsudatähnliche Häutchen, das die Kapsel überzieht, und endlich das häufige Vorkom. men umschriebener, meist ovaler, weißer, oft flach prominenter Ka pselstarfle cken (in Abb. 4 sind zwei solcher weißer umschriebener Flecken zu sehen).

Die Spaltlampenmiskroskopie dürfte berufen sein, in bezug auf die feinere Morphologie und damit vielleicht auch auf die Genese dieser Bildungen bessere Aufklärung zu bringen. So konnte ich im Falle der Abb. 4 (Knabe P. B., 10 Jahre, Veränderung beidseits ähnlich) feststellen, daß die von der Linsenkapsel zum Pupillenrand ziehenden dicken Fäden am letzteren sich blattartig verbreitern, um in den $\mathrm{Pu}$ pillarsaum überzugehen. Die Fäden besteken aus Pigment und weißem Gewebe. Es ist an keinem Faden ein Anzeichen dafür vorhanden, daß er mit der Krause in Beziehung steht. Sowohl hieraus als anch aus der genannten blattartigen Verbreiterung folgt, 
daß die Fäden nicht aus den Gefäßen der Pupillarmembran hervorgegangen sind. Ich möchte sie vielmehr als aus hinteren Synechien durch Dehnung entstandene Gebilde betrachten. Dafür spricht übrigens auch ihre bedeutende Dicke und in unserem Falle noch eine breit ansetzende graue, z. T. pigmentierte Exsudatmembran, welche am einen Auge den unteren Pupillenrand mit der Vorderkapsel verbindet und sich, ebenso wie die Fäden, bei Pupillenverengerung ziehharmonikaartig in Falten legt, um sich bei Erweiterung wieder zu strecken. Für dieselbe Ätiologie sprechen ferner Reste abgerissener Stücke (z. B. Abb. 4 temporal). Mit der entzündlichen Genese steht in Ubereinstimmung, daß das Sternchenpigment der Kapsel in ein graues Häutchen eingebettet liegt.

Die hier angenommene Dehnung fötaler hinterer Synechien zu Strängen findet ein Analogon im postembryonalen Leben, indem das Spaltlampenmikroskop nicht so selten derartige erworbene Bildungen aufdeckt. So sah ich am Spaltlampenmikroskop mehrfach nach lange überstandener Iritis, besonders solcher der Jugend (Keratitis mit Iritis), stark gedehnte, bei Pupillarbewegung ziehharmonikaartig sich faltende und streckende Pupillarmembranen und z. T. auch drehrunde Stränge, von dem Aussehen der kongenital erworbenen. Membranen wie Stränge enthielten z. T. Pigment. Damit dürfte wohl die entzündliche Genese der genannten früh erworbenen Stränge erwiesen sein.

Solange uns die chemisch-physikalischen Bedingungen, welche die Resorption der Pupillarmembran gegen Ende des Fötallebens herbeiführen, nicht bekannt sind, dürfen wir vielleicht die Ursache für die Bildung solcher exsudatähnlicher Membranen und darunter liegender lokaler Linsenschädigungen in Störungen der Resorption vermuten, die evtl. innersekretorischer Art sein könnten und zu entzündlichen Erscheinungen Anlaß gäben. Näher liegt es, als Ursache eine infektiöse fötale Iritis anzunehmen.

Von speziellem Interesse sind die in derartigen Fällen fast stets zu beobachtenden Kapselstarflecken. Ihr Sitz pflegt gewöhnlich nicht ein axialer zu sein. Meist messen die Flecken höchstens einen Millimeter oder nur Bruchteile eines solchen. Durch ihren nicht axialen Sitz unterscheiden sie sich wohl auch der Genese nach von den Polstaren.

Charakteristisch ist die meist schneeweiße Farbe dieser Flecken, ihre scharfe Begrenzung, ihre rundliche bis ovale, häufig radiär gestellte Form, ihre manchmal ausgesprochene flache Prominenz über die Kapseloberfläche und ein von mir nie vermißtes (scheinbares) Fehlen des Linsenchagrins in einer schmalen, den Star umziehenden Zone (chagrinfreier Hof aller Kapselstare, s. unten). Diese Zone bleibt bei Einstellung des Chagrins dunkel und kommt offenbar durch die Krümmungsäncerung in unmittelbarer Näbe des Kapselstars zustande. (Vgl. dieses 
Symptom auch bei anderen Kapselstaren; Verf., Atias der Spaltiampenmikroskopie 1921, Abb. 230.)

Meist adhärieren die oben erwähnten drehrunden Stränge an derartigen Kapselstaren, womit die Ursache der letzteren dargetan ist: sie entstehen durch fötale hintere Synechien. Der Umstand, daß hintere Synechien im postembryonalen Leben nur selten zu Linsentrübung führen, spricht keineswegs gegen die genannte Genese. In fötaler Zeit besorgt die Ernährung der Linse die Gefäßmembran durch die zu dieser Zeit noch besonders dünne Kapsel hindurch. Ein entzündliches Exsudat, das zur Verklebung des Pupillarsaums führt, muß diese Ernährung stören und zur Linsenschädigung Anlaß geben.

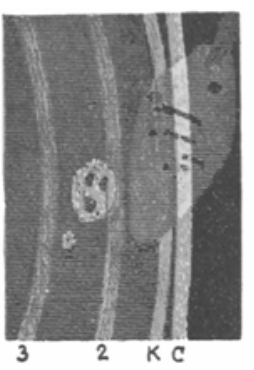

Abb. 4 a.

Im vorliegenden Fall (10jähriger Knabe P. B., bisher nie angenkrank, Eltern und Geschwister gesund, bei dem Knaben keine Zeichen von Lues oder Tbc.) gibt wiederum der ,Abklatsch" einer der genannten Kapseltriibungen im Bereiche einer tiefen Diskon tinuitütsfläehe Kunde von dem trühzeitigen, wahrscheinlich embryonalen Auftreten der Störung. Dieser Abklatsoh ist in Abb. $4 \mathrm{a}$ bei stärkerer (25facher) Vergrößerung wiedergegeben. Wie auch in anderen Fällen ist er im auffallenden Licht le cht gelblich und gehört einer Diskontinuitätszone an (in der Abbildung Zone 2). Die kapsuläre Trübung im Streifen $O$ entspricht dor loffelförmigen Trübung rechts oben in Abb. 4.

\section{Erworbone, gedehnte (bewegliche) Pupillarexsudatmembranen (Abb. 5 und 6).}

Die im Text zu Abb. 4 erwäl nten strang- und membranartig gedehnten linteren Syneclien und entzündlicken Exsudatmembranen sind wohl meist erworbener Natur. - Toh verfüge über eine Reike von Beobachtungen am Spaltlampenmikroskop, wo derartige, bei Pupillenbewegung sich faltende und streckende Stränge und Membranen den Pupillarsaum mit der Linsenkapsel verbinden. Ich gebe kier die Abbildungen von zwei solcten Fällen wieder, bemerke aber, daß ich noch über eine Reihe weiterer Beobachtungen verfüge, so daß die Veränderung nicht so selten ist.

Abb. 5 zeigt die Membran am linken Atge des 46 jährigen Herrn St. Wirt in B., der seit 10 Jahren an beidseitiger rezidivierender Iritis leidet. Wa. neg. Beidseits z. T. gedehnte hintere Synechien, Pigment und Exsudatreste der Vorderkapsel. Augen zurzeit reizlos. Die in Abb. 5 abgebildete blänlichweiße, dichtgefaltete Membran $M$ haftet am nasalen und unteren Pupillarsaum und enthält da und dort etwas Pigment.

Bei enger Pupille liegt die Membran in dichten konzentrischen Falten, bei Mydriasis glättet sie sich, so daß de Verklebungsstellen mit der Kapsel sichtbar werden. Am oberen Ende (bei $R$ ) ein Riiß, der wohl dureh das Pupillenspiel entstanden ist. Ein schmaler derartiger Membranrest, der in drei Zipfeln auf der Kapsel inseriert, ist im oberen Teil der Abbildung (bei $S$ ) zu sehen. Daneben Pigment und fädige Exsudatreste der Vorderkapsel. Jrisgewe he etwas atrophisch. 
Abbildung 6 zeigt durchscheinende, bei unerweiterter Pupille z. T. in die Vorderkammer sich wölbende derartige Membranen am linken Auge der 37 jährigen myopischen Frl. E. G. Auch hier entspringen die Membranen vom Pupillensaum (bei enger Pupille auch noch über die Iris hängend, $\mathrm{Abb}, 6$ ) and inserieren teils in Linien, teils in Flächen auf der Vorderkapsel, wo sie in eine gleichmäßig feine, kaum sichtbare, z. T. mit Pigment bedeckte Exsudatmembran ibergehen (das Pigment hat, wie auch im vorigen Fall, Sternchenform angenommen). Die Iris ist etwas atrophisch und es bestehen zarte hintere Hornhautbeschläge. Die Krause

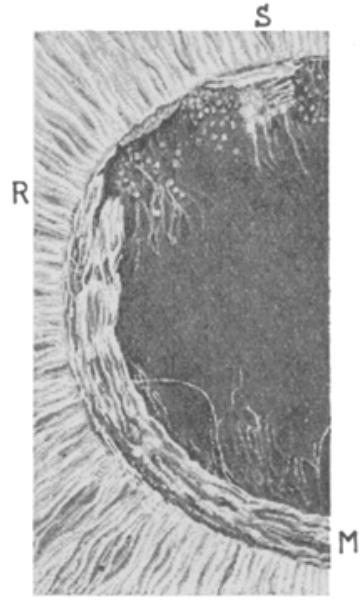

thb. 5.

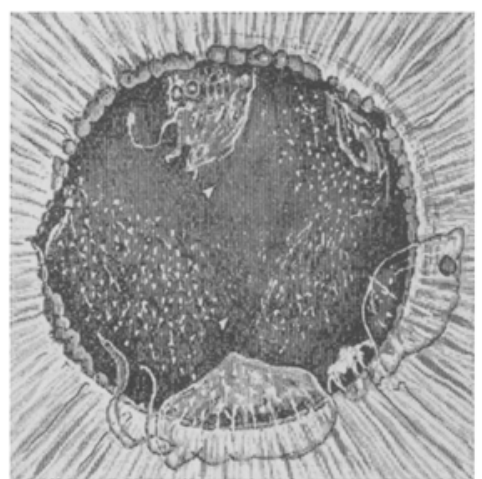

Abb. 6,

ist wenig ausgeprägt, frei von Pupillarfäden. Die Iritis besteht bei reizlosem Auge seit vielen Jahren und hat am anderen Auge zu Erblindung durch Glaukom geführt.

Die Untersuchung 2 Jahre nach Aufnahme der Abbildung 6 ergibt annähernd denselben Befund. Doch ist die temporal-untere Membran von der Linse losgerissen und ragt jetzt als Fetzen frei in die Vorderkammer. An der Hornhautrückfläche immer noch einzelne feine weiße Beschläge, Rechts sehr ausgesprochene, links nasal und temporal beginnende Bandtrübung der Hornhaut. $\mathrm{LS}=6 / 9\left(-6_{90}=\right.$ cyl $2, y_{0}=$ ).

Auch in anderen Fällen von chronischer Iridocyclitis oder von. langjähriger, mit Iritis verbundener Keratitis, sah ich derartige Membrandeknung. Es kandelte sich dabei nur um isolierte kleinere Strangund Membranbildungen. Von ârnlicker Ausdelnung wie im Falle der Abb. 5 sind sie bei dem seit 1918 wegen Keratitis scroplulosa mit Iritis in meiner Behandlung stehenden, jetzt 22 jäbrigen E. H., der seit seinem 12. Jabre an schweren Drüsenerkrankungen und Keratitis leidet. In diesem Falle schien sich die Exsudatmembran des rechten Auges im Laufe der Beobachtungszeit etwas von der vorderen Kapsel loszulösen.

In der Literatur ist, soviel ich sehe, erst eine hierher gehörige Beobachtung niedergelegt, und awar von Axenfeld. (Bewegliche ent- 
zündliche Pupillarmembran, Festschrift für Kuhnt, Zcitschr. f. Augenheillkunde 43, 69. 1920.) In Axenfelds Fall war die Membran von der Kapsel völlig losgelöst in der Pupille ausgebreitet. Anamnestisch ließ sich eine Entzündung nicht nachweisen, doch wiesen Pigmentreste auf dieselbe hin. Gewiß hat auch in unseren Fällen nicht nur Dehnung, sondern z. T. auch Loslösung von der Kapsel zur Bildung der Membranen beigetragen. Die Loslösung findet ein Analogon in den persistierenden Fäden und Netzen der Pupillenmembran, die ja bäufig vollkommen frei über die Pupille sich ausspannen.

$\mathrm{DaB}$ solche Membranen in seltenen Fällen auch angeboren sein können und von der Krause ausgehen, habe ich im Atlas der Spaltlampenmikroskopie bei Abb. 142 beschrieben.

Kongenitale (?) Kapseltrübung mit hinterer Synechie (Abb. 7).

Der 44 jährige Dr. R. stebt wegen Conjunctivitis in Behandlung. Schon vor vielen Jahren hatte ein Augenarzt eine Trübung der linken Linse festgestellt. Irgend. eine Erkrankung oder Verletzung war nach Erinnerung des Pat. und seiner Angehörigen nie vorhergegangen. Bei Erweiterung der Pupille auf $7 \mathrm{~mm}$ sieht man

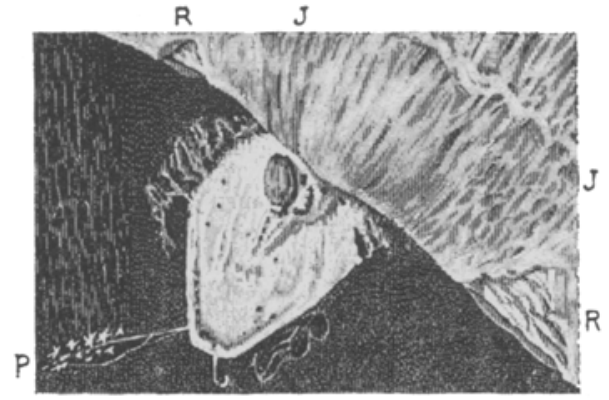

Abbo. 7

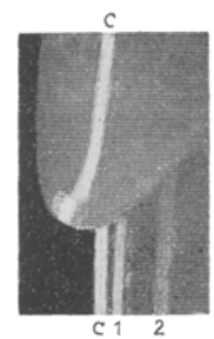

Abo. $7 \mathrm{~b}$.

den weißen, zungenförmigen, z. T. mit Pigment bedeckten Herd der Abb $7 a$. Der Hord ist prominent, schwartig, sein zungenförmiges Ende ist, wie Abbildung $7 \mathrm{~b}$ lehrt, von der Kapsel kammerwärts alobebogen. Nach oben und unten vom Herde einige feine rickzackförmige superficielle Trübungen, medialwärts zwei feine Fäden, die in einen Herd von Sternchenpigment $P$ endigen. Die Iris $J$ ist auf dem Herd fixiert und zwar mittels ihres oberflächlichen Blattes. Es zieht sich infolgedessen bei Mydriasis (Abb. 7 a) der Pupillarpigmentsaum hinter das Stroma zurück. Nach oben und unten vom Herde ist je eine Lücke $\left(R\right.$ und $\left.R^{1}\right)$ des ober. flächlichen Irisstromas za sehen, welche an Risse erinnern. Abb. $7 \mathrm{~b}$ zeigt den Herd im schmalen Büschel, $C=$ Oberflächenstreifen. Man erkennt die zungenförmige Abbiegung der Auflagerung und die Diskontinuitätsflächen (1 und 2) der vorderen Rinde. RS and LS $=8 / 6$.

Trotz des negativen Spaltlampenbefundes der Hornhaut wird man bei dem eigentiumlichen Befunde nicht ohne weiteres auf eine angeborene Veränderung schließen dürfen, sondern anch eine Stich- oder Kontusionsverletzung in Betracht ziehen müssen. 
Reste der Membrana capsulo-pupillaris (Abb. 8).

Unter diesem Namen versteht man, kurz gesagt, die im Bereich der Hinterkammer liegende Partie der Tunica vasculosa lentis, genauer: die Partie peripher der Insertion der ciliaren GefäBe an der Vorderkapsel. Die Membrana capsulo-pupillaris wird demnach gespiesen von den um den Äquator herumkommenden parallelen Gefäßen (eine photographische Aufnahme der letzteren vgl. im Atlas der Spaltlampenmikroskopie Abb. $332 \mathrm{~b}$ ), welche ihr Blut aus den Zweigen der Art. hyaloidea und den Vasa hyaloidea propria erhalten.

Sichere Reste dieser Gefäßmembran bei intakter Iris sind m. W. vor mir erst einmal beschrieben worden, nämlich in einem Falle von Brückner (Abb. 17 seiner zit. Arbeit. In einem zweiten von ihm erwähnten Fall ist das Sternchenpigment meines Erachtens erworben; s, oben Text zu Abb. I). Mehrfach wurden sie dagegen bei kongenitalem Iriscolobom gesehen (Bock, Talko, Lepage; Vossius sah sie bei Irisdefekt). Uber zwei unkomplizierte derartige Fälle habe ich bereits im Atlas der Spaltlampenmikroskopie

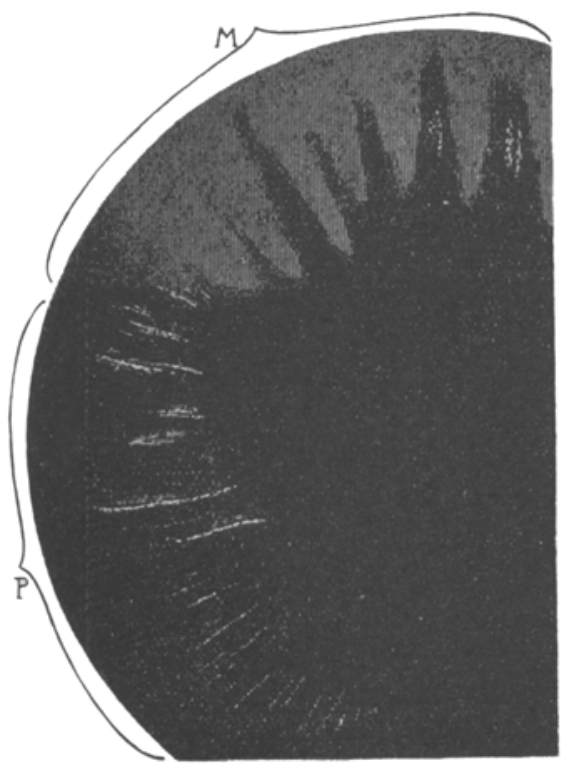

Abb. 8 . Abb. 142 und 215 berichtet. Im Falle der Abb. 142 kann es als fraglich gelten, wie weit die Reste der Membrana capsulo-pupillaris oder aber der Membrana pupillaris angehören. Eine weitere solche Beobachtung gebe ich in $\mathrm{Abb} .8$ wieder.

Bei dem 44 jährigen gesunden Herrn H.P. (Abb. 8, linkes Ange, ca. 14 fach vergr.) sieht man bei dilatierter Pupille beidseits nasale radiäre Pigmentstreifen $P$, welche alle außerhalb des mittleren Pupillarbereiches liegen. Diese radiären Streifen entsprechen der GefäBrichtung, wie sie in der Membrana capsulo-pupillaris et pupillaris vorhanden ist. Herr P., der nie augenleidend war und heute wegen leichter Conjunctivitis in Behandlung steht, hat beidseits braune Tris.

Der während eines Jahres mehrfach kontrollierte völlig stationäre Befund ist folgender: Die Pigmentstreifen $P$ (in der Abbildung die weißen schmalen Linien) sind beidseits nasal, links auch nach oben vorhanden. Am rechten Auge unten sind einige Linien grau statt braun, enthalten also kein Pigment. Die längsten Linien messen ${ }^{3} / 4-1 \mathrm{~mm}$. Bei $4 \mathrm{~mm}$ weiter Pupille sind die axialen Enden einzelner Linien eben erkennbar. Peripher verlieren sie sich rasch. Die Pigmentlinien sind 
bräunlich, höchstens 10 Mikra dick, an den Enden meist zuyespitzt, ganz vereinzelt verdoppelt und lassen eine Zusammensetzung aus feinsten Pünktchen erkennen. tlle stehen radiär, bei einzelnen ist eine leichte terminale Abbiegung erkennbar.

Bei genanerem Zusehen ist besonders am linken Auge nasal und oben wieder jenes merkwürdige Bild vorhanden, das ich, allerdings in viel stärkerer Ausprägung, in Abb. 142 des Atlas der Spaltlampenmikroskopie wiedergegeben und auf die Bogen der fötalen Gefäßsohlingen bezogen habe. (In Abb. 8 die breiten granen Radiärstreifen $M$ mit den dunklen Interstitien, $P=$ radiäre Pigmentlinien, in Wirklichkeit hellbraun.) Eine eigentliche Membranbildung ist aber im vorliegenden Falle, im Gegensatz zu demjenigen dex Abbildung 142, nicht nachweisbar. Oben in der Abbildung ist ensichtlich, daß die radiüren Pigmentlinien in den dunklen Interstitien verlaufen.

Ich hake zur Erklärung der merkwürdigen, von uns zum erstenmal beobachteten Arkaden die konvex nach dem Linsenpol gerichteten GefäBbogen der Pupillenmembran herangezogen. In Abb. 143 des Atlas

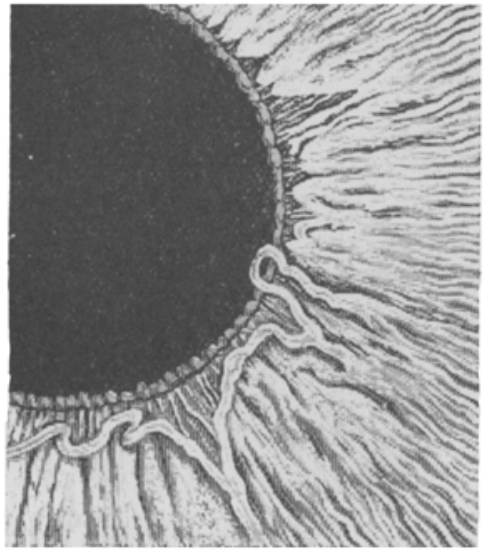

abb. 8 a. der Spaltlampenmikroskopie habe ich die Mikrophotographie dieser Bogen, wie ich sie bei einem 5 monatigen Foe. tus mittels Injektion fand, reproduziert. Es ist ohne weiteres ersichtlich, daß sich von der Peripherie nach dem Zentrum, also radiär, Bogen an Bogen reiht, indem aus der Kuppe oder den Seitenstämmen eines Einzelbogens immer wieder ein Ausläufer hervorbricht, um AnlaB zu einem neuen, axialer gelegenen Bogen zu geben. Es brauchen demnach die Bogenformen unserer $\mathrm{Abb}, 142$ des Atlas der Spaltampenmikroskopie micht den axialen Endbogen zu ent. sprecken, sondern sie können die Arkaden mehr peripker gelegener Partien sein. Dafür spricht ihre rehr peripkere Lage an der erwachsenen Linse.

Dieselben Gebilde führten mich zu einer. Beobachtung, welche die Architektur der Iris betriff. Nicht so selten fand ich die Iriskrause, statt peripher vom Sphincter auf diesen letzteren verlagert, so daß die Krausenstränge den Pupillensaum erreichten, ja ihn gar überdeckten. In solchen Fällen waren dieselben, nach der Linsenachse konvexen Gefäßbogen, welche diefötale Membran auszeichnen, a uf der Krause zu sehen (Abb. 8a). Sie trugen in diesen wie auch in normalen Augen nicht wenig zur Konfjguration des Krausenreliefs bei, welches letztere somit durch die genannten Befunde nnserem Verstänctnis nähor gebracht wind. 


\section{Der chagrinfreie, für den vorderen Kapselstar charakteristische Hof}

(Abb. 3).

1917 (Klin. Monatsbl. f. Augenheilk. 59, 518) beschrieb ich einen (traumatischen) circumscripten vorderen Kapselstar, der bei Chagrineinstellung ringsum einen chagrinfreien Hof zeigte (vgl. Abb. 2 jener Mitteilung). Seither konnte ich diesen chagrinfreien Hof bei jedem vorderen Kapselstar, z. B. bei den Polstaren, nachweisen, während ich ihn bei anderen Trübungen und auch bei Kapselauflagerungen $(z . B$. Resten der Pupillenmembran) vermiBte. Der Hof ist somit für den sog. Kapselstar charakteristisch (vgl. Abb. 184 und 230 des Atlas der Spaltlampenmikroskopie, ferner Abb. 3 dieser Mitteilung). Offenbar beruht er auf einer Niveauänderung des den Kapselstar unmittelbar umgebenden Chagrinsubstrates. Denn durch passende Einstellung gelang es mir nicht selten, den Chagrin im Bereiche des Hofes sichtbar zu machen, wobei er dann in der Umgebung fehlte. Mit Hilfe des Hofes ist mir der Nachweis von sehr kleinen (mikroskopischen) vorderen Kapselstaren gelungen (s. unten).

\section{Mikroskopischer vorderer Polstar (Abb. 10 b).}

Diese bisher nicht beschriebene Starform besteht in kleinen weißen, meist 0,05-0,1 mm messenden Fleckchen, die dicht unter der Vorderkapsel im. Bereiche des Pols oder in dessen Nähe liegen. Bisher sah. ich sie nur in Ein- oder Zweizahl. Sie setzen sich bei 24-37facher und stärkerer Linearvergrößerung an ihrem Rande oft aus Pünktchen zusammen. Daß es sich bei diesen kleinen, bei gewöhnlicher Untersuchung nicht sichtbaren Fleckchen u echtevordere Polstarehandelt, wird durch zwei Momente bewiesen. Erstens fand ich sie bisher nur bei Personen, bei deren Geschwistern oder Eltern gewöhnlicher vorderer Polstar besteht (siehe den unten in extenso mitgeteilten Stammbaum), oder bei denen am zweiten Auge gewöhnlicher Polstar vorhanden war. Zweitens - und das ist der wesentliche Punkt - zeigen diese Polflecketen bei Chagrineinstellung den charakteristiscken oben geschilderten, und z. B. in $\mathrm{Abb}$. 3 abgebildeten e hagrin freien Hof.

Diese mikroskopiscken vorderen Polstare sind somit dem gewöhnlichen bisher bekannten Polstar genetisch gleichwertig.

In einem Falle (linkes Auge des Patienten Hans Schw., des unten stekenden Stammbaums) ist ein solcher Polstar relativ lichtschwach und setzt sich nur aus weißen Pünktchen zusammen. Bei Chagrineinstellung ist zufolge seiner Lichtschwäche vom Star nichts mehr zu seben. An seiner Stelle sitzt aber ein chagrinfreier Fleck, der die Pünktchengruppe an Durchmesser etwa um das Doppelte übertrifft. 
Die Abdrängung vorderer und hinterer Subcapsulärstare durch klare neugebildete Linsensubstanz (,Abklatsch"), mit Bemerknngen zur Genese, speziell zur Heredität vorderer Polstare.

In Abb. 212 und $277 \mathrm{a}$ and $\mathrm{b}$ meines Atlas der Spaltlampenmikroskopie habe ich die Abdrängung traumatisch oder anderswie entstandener subcapsulärer Trübungen durch neugebildete Fasern veranschaulicht. Dort ist auch auf frühere Befunde (Versuche von Leber, v. Hippel u. a.) verwiesen. Experimentell habe ich diese Abdrängung an den an Kaninchen mit Ultrarot erzeugten Staren untersucht, und ich kann heute ergänzend beifügen, daß an den betroffenden Versuchstieren die Abdrängung im Laufe der verflossenen zwei Jahre noch weiter fortgeschritten ist, so daß heute die schalenfömige Trübung eine Schicht einnimmt, welche äquatorial etwa den Linsenradius halbiert. Die Befunde demonstrieren gleichzeitig eine ausgesprochene Volumenabnahme der zentralen Linsensubstanz, also eine Verdichtung der Kernpartien, die vielleicht physiologisch ist. So beträgt bei einem graubraunen, vor 21/2 Jahren bestrahlten, damals ausgewachsenen Kaninchen heute der Äquatorialdurchmesser der (schichtstarähnlichen, schalenförmigen) trüben Partie $9 \mathrm{~mm}$. Berücksichtigt man, daß die Trübung vor $2^{1 / 2}$ Jahren wenige Tage nach der Bestrahlung z. T. subcapsulär, z. T. in der ersten Diskontinuitätszone (Abspaltungszone) lag, so ergibt sich eine Abnahme des damals von der Trübung umschlossenen Äquatorialdurchmessers um 3-4 mm.

Bei Berücksichtigung des Aufbaues der Linse aus ko nzentrischen, aus Faserlagen zusammengesetzten Schalen - die Fasem selber sind im Sinne Rabls zu Radiärreihen übereinander gelagert - ist es verständlich, daß durch Apposition neugebildeter derartiger Schalen die Trübung gleichmäBig in die Tiefe abgedrängt wird. Für den Schichtstar wurde eine derartige Erlklärung schon von Horner aufgestellt und später von einer Reihe von Autoren akzeptiert. Eine Stütze für diese Anschauungen bildet u. a. unsere Beobachtung, daß die abgedrängte Trübungsschale nach Form und Lage vollkommen einer Diskontinuitätszone entspricht.

Am Spaltlampenmikroskop gelang mir der klinische Nachweis derartiger Abdrängung auch an vorderen Polstaren des Menschen recht oft, und ich habe hierfür schon weiter oben zwei Belege gebracht (Abb. 2 und 4). Die Abdrängung kann eine partielle sein (vgl. Abb. 230 des zit. Atlas), wodurch vordere Spindelstare entstehen, die manchmal bis in die Nähe der vorderen Embryonalnaht, häufiger dagegen nur bis in die vorderen Alterskernpartien reichen, manchmal aber auch auf den Cortex beschränkt bleiben, oder aber, was häufiger zu sein scheint, eine totale. Die spindelförmige Einengung kann, wie aus $A b b .3 d$ ersichtlich, eine mehrfache sein. Fs liegt dabei die 
Annahme nahe, daß die ursprüngliche Trübung in axialer Richtung in die Länge gezogen wurde, zufolge des Dickenwachstums der Rinde (Knies u. a.).

Wenn einmal die anatomische und physiologische Grundlage der Diskontinuitätsflächen aufgeklärt sein wird, werden sie uns vielleicht Anhaltspunkte zur ungefähren Beurteilung der zeitlichen Genese derartiger Trübungen bieten. In den von mir bis jetzt beobachteten Fällen war nicht selten erkennbar, daß die ab. gedrängte Partic einer Diskontinuitätsfläche angehörte (z. B. Abb. 2). Auch bei den oben erwähnten multiplen Einengungen des in solchen Fällen zapfenförmigen Stars (Abb.3d) konnte ich die Lage einzelner Trübungsetagen innerhalb Diskontinuitätszonen erkennen. Eine Erklärung für diese merkwürdige Koinzidenz ist einstweilen nicht zu geben. Doch sprechen experimentelle Beobachtungen, die ich mit Ultrarot am Kaninchenauge machte, dafür, daß Diskontinuitätszonen eine Art locus minoris resistentiae für Kataraktbildung darstellen. Wie die schematische Abb. 9 lehrt, liegt nur ein Teil der sofort entstehenden Trübungen dicht unter der Kapsel $C$.

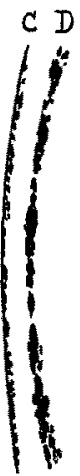

Abb. 9. Dicht unter den subcapsulären Trübungen sind die Linsenfasern lucid, anscheinend intakt. Erst im Bereich der ersten vorderen Diskontinuitätszone $D$ (,,Abspaltungszone ") treten die Trübungen wieder auf, und zwar in besonderer Dichte. Entweder absorbiert also diese Zone die Strahlung stärker, oder aber die ihr zugehörigen Fasern sind gegen die Wirkung weniger resistent (vgl. auch die etagenweise Ausbreitung der Cataracta complicata, z. B. bei Retinitis pigmentosa, wo sich eine zweite Trübungszone häuffig in der Alterskernfläche nachweisen läßt. Verf., Klin. Monatsbl. f. Augenheilk. 62, 601. 1919).

Im Falle der Abb. 2 sitzt die zweite Trübung, der ,Ablklatsch", in einer tiefen Diskontinuitätsfläche (Abb. 2, Zone 2). Fine zweite solche (Zone 1) halbiert etwa die Distanz zwischen vorderer und hinterer Trübung. Eine dritte Diskontinuitätszone, die Abspaltungsfläche, welche dicht hinter der Kapselzone liegt und sich bei verschmälertem Büschel scharf abzeichnet, ist in der Abbildung weggelassen.

In ähnlicher Weise, wie die Diskontinuitätsflächen, bilden, wie ich schon an anderer Stelle ausführte, die Linsennähte Prädilektionsstellen für Trübungen.

Historisch ist zu bemerken, daß, wie auch C.v. Hess erwähnt, bei genauerer Untersuchung schon früher hin und wieder eine „Verdoppelung" des vorderen Polstars im oben geschilderten Sinne beobachtet und zutreffend erklärt wurde. Treacher Collins stellte in derartigen Fällen anatomisch fest, daß die abgedrängte tiefe Starpartie aus kataraktösem Detritus sich zusammensetzt. Bekanntlich besteht der Polstar 
selber teils aus ungeformten, teils aus wenig veränderten Nestern von Kapselzellen, denen manchmal Detritus beigemengt ist. Wobl einen Beweis für eine sukzessive Formung der Trübung liefert der besonders auch klinisch erkennbare geschichtete Bau der in die Vorderkammer prominierenden Partie (Abb. 3, 3a, 3d). Unter dieser kann gelegentlich eine zweite Kapsel mit normalem Epithel sich hinziehen, worauf die leichte Loslösbarkeit des Kataraktzapfens zurückgeführt wurde.

Vergleichen wir die polaren Starformen mit den in $A b b .4$ wiedergegebenen multiplen Starflecken, so fällt der Unterschied in der Struktur auf. Beim Polstar fast regelmäbig die Pyramiden- bis Kegelform und der geschichtete Bau, bei den mit Exsudation einhergehenden, häufig multiplen Starflecken die homogen weiße Beschaffenheit und flache glatte Prominenz. Diese Unterschiede weisen auch auf eine Differenz in der Enstehung hin, ganz abgesehen davon, daß beim vorderen Polstar nicht perforativen. Ursprungs entzündliche Reste zu fehlen pflegen.

v. Hess (Graefe-Sämischs Handbuch III. Bd. 2., T., Kap. IX, S. 216 ; 1911) glaubt, daß Fälle, in denen ein vorderer Polstar als weißer Zapfen eine kleine Strecke weit in die Rinde sich einsenkt, um an seinem hinteren Ende stempelartig sich leicht zu verbreitern (wobei manchmal schwach getrübte Sektoren abgehen), mit der Annabme einer erworbenen Störung durch Perforation schwer vereinbar seien, sich jedoch ungezwungen im Sinne seiner Absclnürungshypothese erklären. Es läßt sioh jedoch demgegenüber mit dem Spaltlampenmikroskop öfters feststellen (vgl. z. B. den Fall der Abb. 10d, vordere Polarkatarakt nach zentraler Hornhautperforation, zentrales Leucoma corneae), daß auch vordere Polstare perforativer Genese sich öfters in die tiefe Rinde erstrecken und dort eine stempelartige Ausbreitung; manchmal auch eine Andeutung radiärer Speickenbildung aufweisen. Es sind solche Fälle eben lediglich der Ausdruck unvollkommener $\mathrm{Ab}$ drängung der trüben Partie durch die neugebildete klare Substanz und beweisen nichts für eine Entstehung durch Störung bei der Abschnürung.

Die fötale Genese vorderer Polstare wird teils per exclusionem (Abwesenkeit früherer Hornhauterkrankungen bzw. Perforationen), teils durch den Nachweis der erwälnten, mit dem Star in Verbindung stekenden Pupillarfäden (Horner, Terrien, Verf.) erwiesen. Der fast stets gleiche $\mathrm{Bau}$, die axiale Lage und nicht zuletzt die fast konstante Größe des angeborenen vorderen Polstars (mittlerer Durchmesser etwa 0,3-1 mm) lassen an eine Entstelungsursacte denken, die in einer entwicklungggeschichtlick en oder anatomiscken Besonderheit des vorderen Pols begründet liegt. Andererseits weist die Tatsache, daß angeborene und durch Perforation erworbene vordere Polstare sich morpholngisch kaum unterscheiden, daranfhin, daß dic 
Ätiologie des angeborenen vorderen Polstars keine einheitliche zu sein braucht.

Die auf dem Polstar sitzenden Pupillarfäden machen es, wie erwähnt, wahrscheinlich, daß der kataraktöse Prozeß in den Zeitabschnitt fällt, in dem eine Gefäßmembran bereits existiert. Die Abschnürung des Linsenbläschens vollzieht sich am Ende des ersten Monats, und während des ganzen folgenden Monats ist von Gefäßen der Pupillarmembran noch nichts zu finden. (Vgl. Kölliker, Zur Entwicklung des Auges und Geruchsorgans mensehlicher Embryonen, Würzburg 1883. Ferner: Bach und Seefelder, Atlas, Taf. VI, VIII, IX, XV.) Sogar ein Foetus von $20 \mathrm{~mm}$ Länge läßt Gefäße in dem präpupillaren Mesoderm noch vollkommen vermissen. Erst zu Anfang des dritten Monats (bei einem Foetus von 27 bzw. $32 \mathrm{~mm}$ Länge, conf. z. B. l.c. Taf. XXVI) sind die ersten Gefäße der Pupillarmembran nachweisbar, aber auch jetzt noch finden sie sjeh ausselließlich peripker und $\mathrm{k}$ aben die vorderen polaren Linsenpartien noch nick.t erreickt. Abscknürung und GefäBmembranbildung fallen also in zeitlich durchaus getrennte Abschnitte der Entwicklung.

Eine Entstekung der Katarakt zur Zeit der Abscknürung des Linsenbläsckens oder kurz nachler wird auch durch den regelmäßig negativen Befund am Embryonalkern unwahrsckeinlich. Vorderer, hinterer und zentraler Teil des Êmbryonalkerns sind in unseren Fällen - mit einer einzigen, noch zu bespreckenden Ausnahme - intakt. Dies ist umso bemerkenswerter, als sich (Zeitschr. f. Augenteilk. 41, 125; 1918 und Atlas der Spaltlampenmikroskopie Abb. 236-259) im Bereich der vorderen embryonalen Y-Naht bei 20 bis $25 \%$ aller normalen Augen eine charakteristische, der Lage und dem Habitus nach konstante, mit keiner anderen Linsenveränderung $\mathrm{zu}$ verwechselnde schneeweiße Trübungsform findet, die nach ihrer Lage im vorderen Embryonalnahtgebiet in die erste Zeit der Linsenentwicklung, wahrscheinlich etwa in die Zeit der Abschnürung oder die ihr unmittelbar folgende Epoche zu verlegen ist, und die wir als „,vordere axiale Embryonalkatarakt" bezeicknet haben. Demgegenüber ergeben unsere Befunde beim vorderen Polstar, da $B$ die Fasern gerade der ältesten Linsenpartien, welche diesen ersten Embryonalmonaten ihre Entstehung verdanken, in den Fällen von vorderem Polstar vollkommen klar und intakt sind. Also gerade diejenigen Fasern, welche sich in der Zeit der angenommenen Störung der Abschnürung entwickelt haben müssen. Und umgekehrt betrifft die Erkrankung (i.e. Katarakt) gerade jene Linsenfasern, welche erst dem späteren Embryonalleben, der Zeit, da die Tuniea vasculosa längst bestand, oder etwa der Rückbildungsepoche der Tunica vasculosa ihre Entstehung verdanken: die Fasern 
der den Embryonalkern umschließenden and die Rinde bildenden Partien.

Mit Vorstehendem ist natürlich die Möglichkeit nicht abgelehnt, daß kataraktöse Veränderungen bzw. Linsenmißbildungen gelegentlich auch durch Störungen in der Abschnürung des Bläschens verursacht werden, etwa in der Weise, wie dies der bekannte Hesssche Befund an einem Hähnchenembryo dartut. Aber die von uns bis jetzt untersuchten vorderen Polstare bieten für die Abschnürungshypothese keine Stützpunkte. Die Intaktheit des ganzen, der ersten Embryonalzeit entstammenden Linsengebietes spricht gegen eine Abschnürungshypothese und macht es wahrscheinlich, da $B$ die meisten a ngeborenen vorderen Polstare einem späteren Abschnitt des Em. bryonallebens ihre Entstehung verdanken.

DaB nicht alle kongenitalen vorderen Polstare derselben Epoche des fötalen Lebens entstammen, macht sehon der Umstand wahrscheinlich, daß die Trübung in sehr wechselnde $m$ Grade in die Tiefe sich fortsetzt. In einem Falle (Abb. 1la) fand ich die etagenförmig übereinanderliegenden Kataraktschichten mit kräftiger ,,vorderer axialer Embryonalkataralkt" kombiniert (am zweiten Ange bestand diese allein, Abb. 11 b). Eine derartige Kombination ist bei der Häufigkeit der letzteren Starform wohl durch Zufall bedingt.

Noch weniger Klarheit als über die zeitliche Entstehung herrscht über die Ätiologie der vorderen Poltrübungen. Die stets axiale Lage weist immerhin auf die Möglichkeit hin, daß die Ursache gelegentlich in entwicklungsgeschichtlichen oder normalanatomischen Besonderheiten des vorderen Linsenpols zu suchen ist. In dieser Hinsicht ist. beachtenswert, daß bei Katarakt durch Hornhautperforation die Trübung auch dann am vorderen Pol sitzt, wenn die Perforationsoffnung peripher liegt (Deutsehmann, Sehweigger, Treacher Collins, E. Fuchs, Tertsch, Terrien u. a.).

Die Ursache dieses Verhaltens ist nicht klar, wenn auch die Annahme nahe liegt, daß die peripheren Partien im Gegensatz zu den axialen durch die Tris geschützt werden. Aber auch für Cataracta complicata (z. B. durch Amotio retinae) sind vorderer und hinterer Pol Prädilektionsstellen. Vielleicht ist für letzteren Umstand das Zusammentreffen der Nähte an den Polen verantwortlich zu machen.

Des weiteren möchte ich auf gewisse Besonderheiten der fötalen Gefäßversorgung des vorderen Pols hinweisen, welche evtl. für die isolierte Starbildung desselben von Bedeutung sein könnten. Löst man die Pupillenmembran sorgfalltig von der Vorderkapsel, so bleibt regelmäßig der axiale Teil hängen. Die losgelöste Membran hat ein zentrales Loch. Diese Beobachtung haben schon vor uns Bach und Seefelder niedergelegt. Es folgt ans ihr, daß die Pupillar- 
membran am vorderen Linsenpol besonders solid mit der Kapsel verlötet ist.

Eine andere Besonderheit der Gefäßmembran im Bereiche des vorderen Linsenpols ist schon lange bekannt und hat seiner Zeit zu unrichtigen Vorstellungen über den Bau der Membran geführt. Die Besonderheit nämlich, daß die Gefäße des vorderen Pols aus Anastomosen zwischen den Enden der Radiärschlingen bestehen (vgl. Abb. 143 bis 144 meines Atlas der Spaltlampenmikroskopie), und daß sie zuletzt sich bilden und zuerst sich zurückbilden. Normalerweise sind diese axialen Verbindungsgefäße anscheinend zu einer Zeit resorbiert, zu der die Schlingen noch vorhanden sind. Dies gilt nicht nur für das menschliche Auge. Neugeborene Kaninchen oder Katzen z. B. zeigen den polaren Teil der Linse häufig gefäßlos. Diese Tatsachen hatten zu der Vorstellung Anlaß gegeben, daß der vordere Pol überhaupt gefäßfrei sei. O. Schultze (Festschr.f. Kölli ker, Leipzig 1892 S. 7) hat aber nachgewiesen, daß das gefäBfreie Stadium das erste Stadium der Resorption darstellt, und daß auch der vordere Linsenpol, eine Zeitlang wenigstens, vascularisiert ist. Immerhin lehren diese Tatsachen, daß der genannte Linsenabschnitt in bezug auf seine Gefäßversorgung besonderen Bedingungen unterworfen ist (was übrigens schon ein Blick auf die zitierte Abb. 143 lehrt, welche eine Mikrophotographie beim fünfmonatigen Föten darstellt). Daraus folgt aber, daB auf diesen Abschnitt beschränkte, für ihn typische Zirkulationsstörungen möglich sind. Worin diese evtl. bestehen würden und auf welche Art sie zur Poltrübung führten, ob durch Ausbleiben der erwähnten Anastomosenbildung, ob durch verfrühte GefäBrückbildung oder endlich durch entzündlicke Veränderungen - wie sie in anderen Endschlingennetzen (z. B. Limbus, Macula) nicht selten auftreten -, entzieht sich unseren Kenntnissen. Auf alle Fälle ist die Möglichkeit einer solchen Entstehungsweise von vornherein nicht abzulehnen.

Daß aber derartige Faktoren vielleicht doch nicht oder nur ausnahmsweise für die Entstehung des Stars bestimmend sein können, lehrt uns schon das Vorkommen ganz homologer, ähnlich geformter hinterer Polstare. Die geschilderten anatomischen Verhältnisse kommen hier nicht oder nur teilweise in Betracht.

Schwerwiegender als alle erörterten Momente ist die Tatsache des hereditären Charakters vorderer Polstare. Sie weist uns daraufhin, daß bestimmte Zellabschnitte zufolge entsprechender Beschaffenheit des Idioplasmas in bestimmten Lebensabschnitten der Degeneration verfallen. Untersucht man systematisch die Familienangehörigen mit Polstar Behafteter, so findet man oft mehrere Glieder und gelegentlich auch Vorfahren betroffen. Kinderreiche Familien bieten hierbei am Spaltlampenmikroskop ánBerordent- 
lich instruktive Befunde, welche auf den Polstar nach Genese und Morphologie ein nenes Licht zu werfen geeignet sind.

Als Beispiel teile ich folgenden Fall in extenso mit.

$1919 \mathrm{kam}$ der 1906 geborene Hans Schw. in B. wegen eines seit Geburt be. stehenden weiBen Fleckchens in der rechten Pupille in unsere Poliklinik. Der Knabe hat neun (lebende) Geschwister von 9-19 Jahren, die ich alle, wie aueh die beiden Eltem, am Spaltampenmikroskop untersuchen konnte. Der Stammbaum ist der nachfolgende.

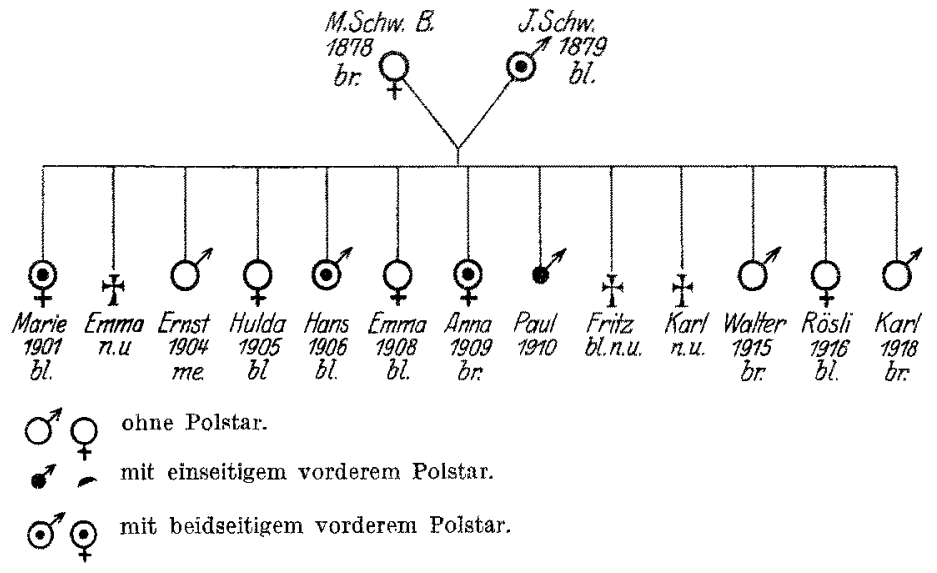

Die Untersuchung fand im September 1921 am Spaltlampenmikroslzop bei unerweiterten Pupillen statt.

Aus diesem Stammbaum ist ersichtlich, daB die Mutter zwar vordere axiale Rindennahtpunktierung (cine nicht seltene senile oder präsenile Veränderung, (s. den späteren Abschnitt, ,Altersveränderungen "), jedooh keinen vorderen Polstar aufweist. Der Vater dagegen zeigt links den runden vorderen Polstar $P$

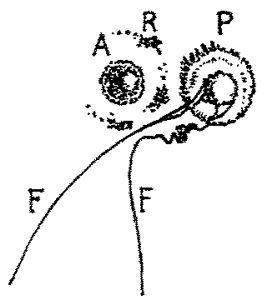

Abb. 10 a. der Abbildung 10a, der einen Durchmesser von $0.4 \mathrm{~mm}$ aufweist und dessen mittlere Partie zapfenförmig in die Vorderkammer vorragt. Von dem Zapfen aus gehen zwei Pupillarfäden $F$, die stellenweise etwas membranös-spinnwebig verbreitert sind, nach unten und unten-innen, um nach Cabelung an der Krause zu inserieren. Der vom Polstar völlig getrennte. Abklatseh $A$ sitzt ein weniges hinter der Alterskernfläche, welche letztere beidseits ein kräftiges, feinfirstiges, distinktes Relief darstellt. Mit dem verschmälerten Nitrabüschel ist ersichtlich, daß der Abklatseh zwisohen Relief und vorderer Embryonalnaht sitzt, jedooh dem Relief wesentlich genähert ist, sò daß sich die Distanz vom letzteren zu derjenigen von der Naht wie $1: 2$ verhält. Der Abklatsch hat einen Seheindurchmesser von 0,28 mmo, ist jedoch in einiger Distanz von einem lückenhaften Trübungsring $R$ umfaßt, den ich auch in andern Fällen sah, und dessen Lumen hier 0,6 mm miBt (Abb. 10a). In der Mitte des Abklatsches sieht man eine feine, nach rorn gerichtete Prominenz.

Das ganze Gebilde weist etwa denselben Typus auf, wie sie Abb. 2 für den Sohn Hans Schw. wiedergibt, mit der einzigen Ausnahme, daß die Pupillenfäden beim letzteren nach oben, beim Vater aber nach innen-unten ziehen. Auch 
wird die Sehschärfe des linken Auges des Vaters, im Gegensatz zu der des Sohnes, durch die Katarakt nicht wesentlich beeinträchtigt. Sie beträgt schwach $6 / 6$.

Das rechte Auge des Vaters zeigt den oben beschriebenen ,mikroskopischen vorderen Polstar" (Abb. 10b, P), indem, wie am linken Auge des Sohnes Hans und an den beiden noch zu besprechenden Linsen der Tochter Anna ein 0,08-0,1 mm messendes rundliches Fleckehen ziemlich genau in der Pupillenmitte liegt. Ein feinstes Fädchen zieht von der Trübung nach unten, um sich bald zu verlieren. Bei Chagrineinstellung zeigt uns die Trübung den charakteristischen chagrinfreien Hof. Nach oben, in einigem Abstand, eine kurze vertikale Reihe von Pigmentsternchen (Abb. $10 \mathrm{~b}$ bei $S$ ).

Von den 13 Kindern dieses Mannes sind drei gestorben (eines Abb. $10 \mathrm{~b}$ durch Unfall, eines durch Frühgeburt und eines an ,Magenkrämpfen", letzteres mit 7 Wochen). Von den zehn lebenden, mit Ausnahme der ältesteu, etwas anämischen Tochter, gesunden, kräftigen Kindern, sind vier mit Polstar behaftet, zwei Mädchen und zwei Knaben.

Beidseitigen vorderen Polstar mit Abklatsch zeigt die älteste (19jährige) Tochter Marie Schw. Rechts ist er rundlich, leicht prominent, mißt 0,8 mm, der Abklatsch etwas mehr. Konzentrische Schichtung ist erkennbar (Abb. 10c). Links ist er vertikal oval, mißt 0,4 zu $0,8 \mathrm{~mm}$ und es sehließt sich im letzteren Falle eine Pigmentsternchengruppe an. $\mathrm{RS}=6 / 9, \mathrm{LS}=6 / 24$ ohne Glas.

Der 1904 geborene Ernst weist klare Linsen auf. Den rechtsseitigen Star des darauffolgenden Hans (geb. 1906) haben wir bereits besprochen und in Abb. 2 abgebildet. Das linke Auge des Hans zeigt wiederum den mikroskopischen vorderen Polstar. Er sitzt $0,12 \mathrm{~mm}$ nach oben und etwas nach außen über dem linken Pupillenmittelpunkt, genau in einer Nahtgabel, ist rechteckig und mißt horizontal 0,08 , vertikal $0,04 \mathrm{~mm}$. Unterhalb dieses Fleckchens zwei weiße Pünktchen, die wie die Haupttrübung bei Chagrineinstellung als chagrinfreie (schwarze)

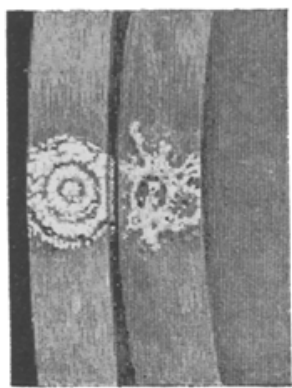

Abb. $10 \mathrm{c}$. Flegkchen sich abheben. Diese Flecken haben dann etwa den doppelten Durchmesser der Trübungen. Das nächstfolgende Kind (Emma, 1908) hat intakte Linsen. Dagegen sind beide Augen der 1909 geborenen Anna mit mikroskopischem vorderen Kapselstar behaftet. Rechts sind zwei solcher weißer Fleckehen vorhanden, die schräg vertikal in Distanz von $0,28 \mathrm{~mm}$ übereinander stehen. Die Fleckchen sind rundlich und messen je $0,06 \mathrm{~mm}$. Links besteht dagegen nur ein solches Fleckchen von quer rechteckiger Form $(0,08 \mathrm{zu} 0,05 \mathrm{~mm})$, dessen untere innere Ecke sich in eine Pünktchenreihe verliert. Es liegt wieder ca. $0,12 \mathrm{~mm}$ oberhalb Pupillenmitte. Charakteristisch ist auch hier ein chagrinfreier Hof.

Das nächste Kind Paul (1910) ist wieder durch einen rechtsseitigen kräftigen vorderen Polstar ausgezeichnet, von fast genau dem Typus wie beim Sohne Hans. Vier stellenweise membranös verbreiterte Pupillarfäden ziehen, ganz ähnlich wie beim letzteren, von der Kuppe des Polstars nach obe n, um nach Gabelung an der oberen Krause $\mathrm{zu}$ inserieren. Durchmesser des rundlichen Stars $0,3 \mathrm{~mm}$, Mittelteil zapfenförmig prominent. Abklatsch eckig, in der Gegend des Alterskernstreifens mißt er horizontal 0,16 , vertikal $0,12 \mathrm{~mm}$, und ist umfaßt von einem rudimentären, aus ein paar Fleckchen bestehenden Ring von $0,4 \mathrm{~mm}$ Durchmesser. Das linke Auge dieses Knaben ist frei. Die drei letzten Kinder, von denen der 3 jährige Karl wehen Unruhe nicht sehr genau untersucht werden konnte, zeigen keine vorderen Poltrübungen. 
Es sind somit in diesem Stammbaum drei Polstartypen vorhanden:

1. der gewöhnliche, konzentrisch geschichtete Pyramidalstar mit Abklatsch;

2. der vordere Pyramidalstar mit Pupillarfäden und Abklatsch;

3. der mikroskopische vordere Kapselstar. Letztere beiden Formen sind in zwei Fällen gleichzeitig beim selben Individuum vorhanden.

Alle diese vorderen Polstarformen, makroskopische und mikroskopische, pyramidale und flache, solche mit und solche ohne Pupillarfäden oder Abklatsch sind somit nach unserem Stammbaum als genetisch gleichwertig zu betrachten. Wir dürfen sie als die Variationsformen des vorderen Polstars bezeichnen.

§ Bei einer nicht gerade häufigen Anlage, wie sie der vordere Polstar darstellt, und bei gleichzeitigem Fehlen von Verwandtenehe, kann mit großer Wahrscheinlichkeit angenommen werden, daß die Anlage bei dem Vater Schwob heterozygot vorhanden ist. Wird das Gen für normalen vorderen Linsenpol mit $P$, dasjenige für Polstar mit $p$ bezeichnet, so ergibt sich. die Kreuzungsformel

$$
P P \times P p=2(P p+P P) .
$$

In Worten: die Hälfte der Kinder (große Nachkommenzahlen vorausgesetzt, wie sie beim Genus homo ja nie vorkommen) ist befallen, die Hälfte frei. Von zehn Kindern der Familie Sch. sind vier, somit $40 \%$ befallen.

Wir können somit sagen, daß der Polstar sich in unserer Familie nach gewöhnlicher Mendelscher Regel vererbt, und daß ferner $p$ über $P$ dominant ist, da $B$ also der vordere Polstar in unserer Familie ein dominantes Merkmal darstellt, dessen Vererbung dem Me ndel schen Gesetze untersteht.

Der vordere Polstar ist ein, wenn auch nicht gerade häufiges, so doch bei genauer Untersuchung nicht sehr seltenes Vererbungsmerkmal. Auf alle Fälle ist er viel häufiger als etwa der Totalstar. Im Zusammenbang hiermit stehen die hier nachgewiesene Dominanz und der Umstand, daß er die Sehschärfe relativ wenig (in unserer Familie unter neun Augen nur dreimal und nicht sehr wesentlich) beeinträchtigt. Dominante Leiden, die die Existenzbedingungen emstlich gefährden, wie etwa angeborener Totalstar, wirken ausmerzend und sind infolgedessen sehr viel seltener.

SchlieBlich ist in unserem Falle auch noch die Vererbung der Irisfarbe von Interesse. Die Mutter hat hellbraune, der Vater blaue Iris. Drei der befallenen Kinder haben blaue, eines aber (Anna) braune Iris. Es besteht daher keine Korrelation zwischen Irisfarbe und Trübung. Bei einem Soln (Ernst, 1904) besteht insofern eine Art 
Mosaikvererbung der Irisfarbe, als die Partien peripher der Krause mehr blau, die innerhalb derselben bräunlich sind. Von den übrigen Kindern (die Farbe ist auch noch von dem mit 7 Jahren verstorbenen Fritz bekannt) haben sieben blaue, drei braune Farbe. Bekanntlieh ist die braune Irisfarbe über die blaue dominant; vgl. G. C. und Ch. B. Da ven port (Science 26, 589; 1907 und American Naturalist 44; 1910), ferner C. C. Hurst (Roy. Soc. Proc. 80 B; 1908); vgl. auch Ant. Lutz (Arch. f. Ophthalmol. 79, 408; 1911).

Über die Anlage der Irisfarbe der Eltern unseres Stammbaums bestehen zwei Möglichkeiten:

1. bei der Mutter ist die braune (br), beim Vater die blaue (bl) Anlage homozygot: br br $\times \mathrm{bl} \mathrm{bl}=4 \mathrm{br}$ bl. Dieser Fall kann nicht zutreffen, da sämtliche Kinder braune Augen haben müßten.

2. Die braune Irisfarbe der Mutter ist heterozygot (br bl), die blaue des Vaters homozygot: br bl $\times$ bl bl $=2(b r b l+b l b l)$. Die Hälfte der Kinder haben braune (dominant heterozygot), die andere Hälfte hat blaue Iris (recessiv homozygot). Dieser z weite Fall $m u ß$ in unserem $\mathrm{Sta} \mathrm{m}$ ba u realisiert sein.

Die Eltern des Vaters waren somit in bezug auf die blaue Irisfarbe entweder beide heterozygot, oder der eine heterozygot braun, der andere homozygot blau, oder endlich es waren beide homozygot blau. Die Eltern der Mutter konnten in bezug auf braune Irisfarbe nicht homozygot sein, während alle übrigen vier Möglichkeiten vorhanden sind:

$$
\begin{aligned}
& \text { br br } \times \text { br bl } \\
& \text { br br } \times \text { bl bl } \\
& \text { br bl } \times b l b l \\
& \text { br bl } \times \text { br bl }
\end{aligned}
$$

\section{Durch Perforatio corneae post natum exworbener vorderer Polstar (Abb. 10 d).}

Der 37 jährige E. F. machte nach der Geburt eine Augeneiterung durch. Heute linke Hornhaut mit zentralem Leukom, vorderer Linsenpol mit umschriebener Trübung, die sich duroh die vordere Rinde in die Tiefe senkt, um sich dort stempelartig zu verbreitern. Von der Verbreiterung aus gehen mehrere Radiärstrahlen (Abb. 10d). Der dichteste Teil der Trübung liegt axial, im Bereiche der Vorderkapsel. In ihrer Mitte erkennt man eine deutliche, gut begrenzte Einsenkung, welche den Eindruck eines Substanzverlustes macht. Die Vertiefung hat steile Ränder,

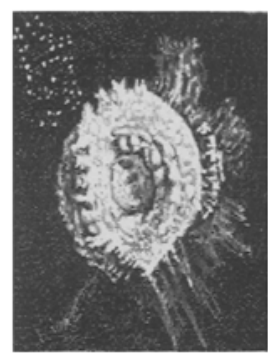

tbb. $10 \mathrm{~d}$. ist unregelmäßig eckig, mißt vertikal 0,28 , horizontal $0,24 \mathrm{~mm}$. Der Vertikalsdurchmesser der Gesamttrübung $1,2 \mathrm{~mm}$. Nach oben von der Trübung bräunliches Vorderkapselpigment.

Die Katarakt unterscheidet sich in keiner Weise von angeborenen vorderen Polstaren. 


\section{Vordere Pyramidalkatarakt kombiniert mit vorderer axialer Embryonal- katarakt (Abb. 11 a und b).}

Bei der 12 jährigen $J$. B. bestehen links die drei hintereinanderliegenden Trübungen der Abbildung 11 a. Vorn der mit der Spitze in die Vorderkammer ragende Polstar $P$. In einer feinen Diskontinuitätszone $N$ liegt ein ähnlich groBer (im auffallenden Licht gelblicher) Abklatsch mit unregelmäBiger konzentrischer Ringzeichnung. Im Bereiche der vordern Embryonalnaht $E$ eine schneeweiße, typische, zweiteilige , „vordere axiale Embryonalkatarakt" typus und fingerartige Zeichnung aufweist. Größe dieses Teiles: vertikal 0,44 , horizontal $0,36 \mathrm{~mm}$, Lage ca. $0,5 \mathrm{~mm}$ unterhalb Linsenaxe. (Der Pyramidalstar miBt $0,46 \mathrm{~mm}$.) Die obere kleinere Embryonalkatarakt liegt im Kreuzungspunkt des vorderen $Y$, eine Spur dahinter, und miBt 0,15 $\mathrm{mm}$. Das verschmälerte Büschel läßt erkennen, daß der, ,Abklatsch" dem Polstar etwas näherliegt, als dem Em-

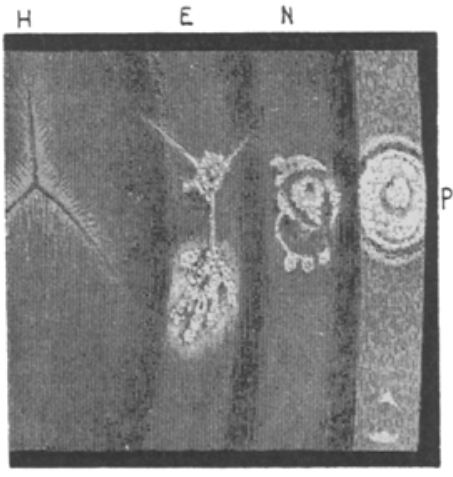

Abb. 11 a.

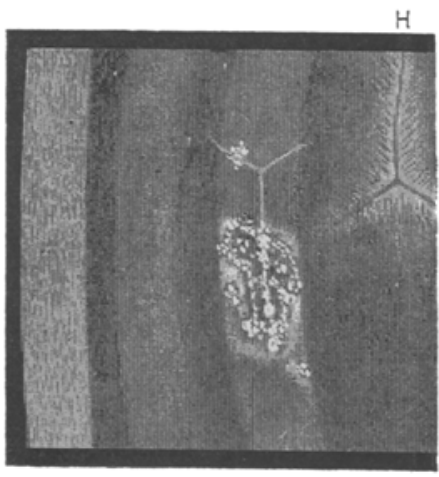

Abb. $11 b$.

bryonalstar. Am linken Auge starker querer Pupillariaden, der die Pupillenränder verbindet, ohne Kontinuität mit dem Polstar oder mit der Kapsel.

Bemerkenswerterweise ist am anderen (rechten) Auge nur eine Embryonal. katarakt vorhanden, von Polstar und Abklatsch fehlt jede Spur, wohl ein Wahrscheinlichkeitsbeweis dafür, daß am linken Auge vorderer axialer Embryonalstar und Polstar zufällig zusammengetroffen sind. Auch am rechten Auge (Abb. 11 b) zerfällt die Embryonalkatarakt in einen oberen kleinen und einen unteren größeren Teil. Der obere Teil miBt jedoch hier nur ca. $0,05 \mathrm{~mm}$ und liegt ein wenig ne ben (und hinter) dem Nahtpunkt.

Hintere Embryonalnaht beidseits intakt (Abb. $11 \mathrm{a}$ und $\mathrm{b}, H$ ), beidseits normaler Hyaloidearest.

\section{Die Konvergenz der vorderen Diskontinuitätsflächen im Bereich. des Polstars.}

\section{Darstellung des Yerlauf́s der Diskontinuitätsflächen mittels schmalen Büsehels (Abb. 12).}

Es handelt sich um den Schichtstar der Abbildung 235a (5jähriges Mädchen S. K.) des Atlas der Spaltlampenmikroskopie. Der Star erreicht die vordere Kapsel, der Kern ist verhältnismäBig klar. Anscheinend erreicht die Trübung auch den hinteren Pol, doch ist darïber nicht volle Sicherheit zu gewinnen. In Abbil- 
dung 12 sieht man bei 24 facher Linearvergrößerung den Kapselstreifen $C$ im Bogen über die rundlich prominente Poltrübung $P$ ziehen. Die Prominenz ist nicht überall gleichmäBig, am stärksten ist sie im nasal unteren Teil der Trübung. Der $\mathbf{A b}$ spaltungsstreifen 1 nähert sich nach der Poltribung hin dem Streifen $C$ bis zur Versohmelzung, wird innerhalb der Trübung $P$ unseharf, wobei er anseheinend im Bogen nach hinten biegt, also nach vorn konkav verläuft. Die nachfolgenden Streifen 2 und 3 , in deren Bereich sich der zweite, tieferliegende Trübungshof ausbreitet zeigen streifige Struktur und konvergieren ebenfalls stark nach der vorderen Trübung hin, in diese sich verlierend.

Eine solche Konvergenz sah ich ofters bei Polstaren. Sie kommt offenbar dadurch zustande, daß beim Linsenwachstum die Apposition neuer Fasern im Bereich des Stars nicht stattfinden kann. Daß die neugebildeten Fasern die Starmassen von der Kapsel abzu drängen versuchen, beweisen die Abkjatschstare (Abb. 2, 3, 4a, 10a u. b. usw.). Gelingt die Abdrängung nicht, setzt die Trübung der Apposition, einer fixen Narbe gleich, ein Hindernis entgegen, so muß die Konvergenz der

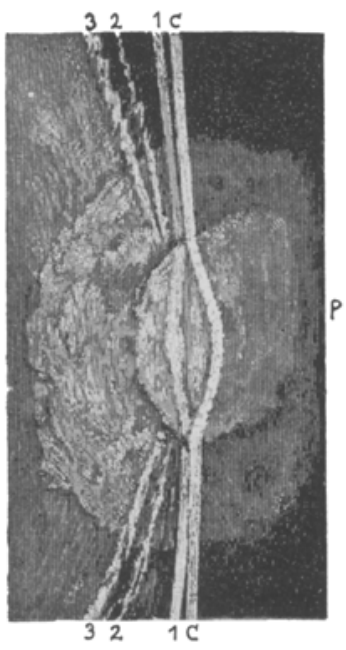

Abb. 12. Diskontinuätsflächen entstelen, wie sie in Abb. 12 verwirklicht erscheint. Die praktisch wichtige Folge hiervon ist eine $\mathrm{Hem}$ mung dessagittalen Dickenwachstums der Linseim Bereiche des Stars und seiner nächsten Umgebung, ein Umstand, der uns vielleicht die geringe Dicke mancker derartiger Linsen erklärt. In der schematischen Abb. 14 konvergieren die Diskontinuitätszonen nach den beiden Kernpolen, in deren Bereich eine Trübung angenommen ist (Abb. 13 normale Linse). Es resultiert eine.Linsenform, welche etwa an diejenige eines roten Blutkörperclens erinnert (Abb. 14). Die Konvergenz der Diskontinuitätszonen zu einem Punkte veranscl aulicht in dieser Abbildung das Ausbleiben des Rindenwachstums im Bereiche

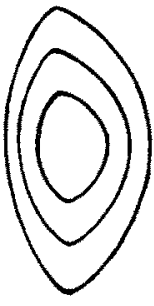

Abb. 13 .

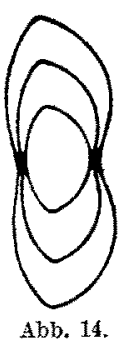

der beiden Pole. Derartige Linsenformen sind bei angeborenem und erworbenem Star in der Tat beobachtet. Knies (Arch. f. Ophthalmol. 93, 1, 212; 1877) Lat bei Spindelstar mehrfach Dellen des vorderen Pols festgestellt. Vossi us (Beitr. z. Augenheilk. 1; 1893, Zur Kasuistik der angeborenen Anomalie des Auges, $\mathrm{Abb}, 6$ ) fand nach Perforatio bulbi infolge Pocken anatomisch eine Linse, deren Sagittalsclnitt etwa Brillenform aufwies. Eine ähnliche Deformierung (,,blutkörperchenförmig ${ }^{c}$ ) bildet $\mathrm{C}$. v. Hess in einem seiner Fälle von Zentralstar ab (1. c. Abb, 36), 
Es sind solche Beobachtungen das extreme Resultat jener Wachstumshemmung, welche die Kapsel- bzw. Spindelkatarakt in der oben dargelegten Weise zur Folge haben muß.

Da:B auch eine Verlagerung des Kerns auf diese Weise sich vielleicht erklären ließe, sei nur angedeutet. (Verlagerungen des Kerns, z. B. nach dem hinteren Pol, sind anatomisch von Schirmer [Arch. Graefes f. Ophthalmol. 35; 1889], Onken [Arch. f. Augenheilk. 42; $1900]$ und v. Hess [1.c. S. 194] beobachtet.)

\section{Hinterer Polstar in Kombination mit radiärstreifiger Katarakt des vor- deren polaren Rindenabschnittes (Abb. 15a, b).}

Bei dem 36 jährigen Rüd. Jos. mit RS und LS $=\operatorname{schwach} 6 / 6$ bestebt beidseits eine runde flache, unbedeutend in die hintere Rinde prominente Katarakta

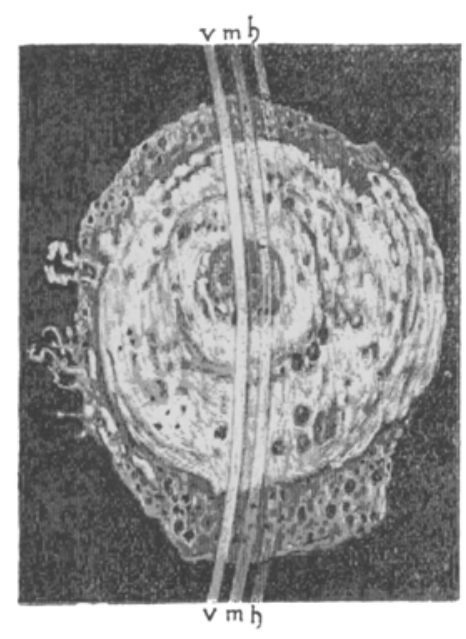

Abb. $16 \mathrm{a}$.

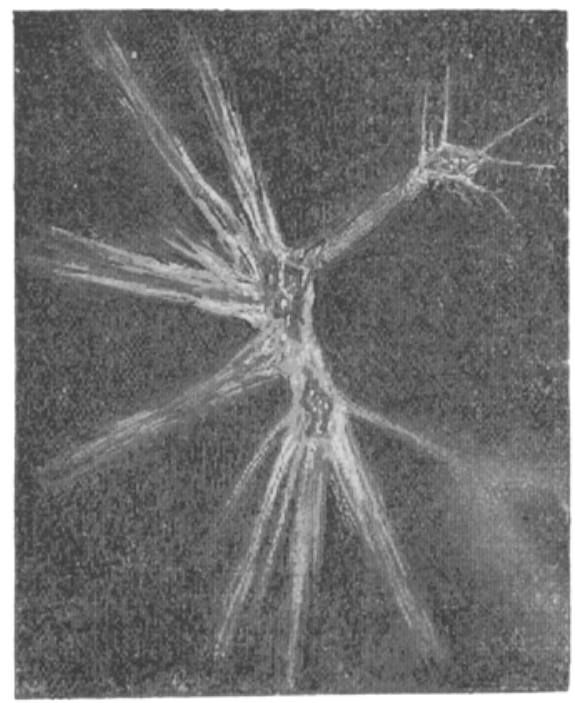

$4 \mathrm{bb}, 15 \mathrm{~b}$

polaris post (Abb. 15a). Sie ist auf beiden Augen insofern von ähnlicher Struktur, wie die in Abb. 234 des Atlas der Spaltlampenmikroskopie wiedergegebene, als sich konzentrische Zonen unterseheiden lassen und eine Art Hofbildung erkennbar ist. Doch ist im vorliegenden Fall die Prominenz eine ganz unbedeutende, schatzungsweise kaum ein Fünftel der Flächendimension betragende, und rechts weist der mittlere Teil der Trübung sogar eine leichte Vertiefung auf. Der "Hof“ ist nichts anderes als eine lockere, in größerer Nähe der Hinterkapsel gelegene Trübungspartie. An ihr tritt der poröse, z. T. löcherige Bau noch deutlicher zutage als an der Haupttrizbung. Der scheinbare Durchmesser der Trübung inklusive Hof beträgt rechts horizontal 1,68, vertikal 2,08 , links horizontal 2,0 , vertikal $2,2 \mathrm{~mm}$. Drei Diskontinuitätsflächen sind im Bereiche der Trübung nachweisbar (s.Abb. 15a). Die vorderste derselben, $V$, biegt in sanfter Wölbung itbex die Trübung, in deren 
Vorderfläche übergehend. Die hinterste, $h$, wird durch die Hinterkapsel repräsentiert, und biegt, wie am Rande der Katarakt ersichtlich, etwas nach hinten aus (in der Abbildung nicht dargestellt). Es erzeugt somit die Trübung im Bereiche der Hinterfläche eine leichte Prominenz nach dem Glaskörper. - Der physiologische Hyaloidearest und die Bogenlinie sind nicht zu sehen. Vordere und hintere Embryonalnaht sind intakt. - Was den vorliegenden Fall besonders auszeichnet, ist eine gleichzeitig vorhandene, bisher nicht beobachtete, strahlige Trübung der axialen vorderen Rinden partien, an welcher Kern und Kapsel völlig unbeteiligt sind. Die meist den Nähten folgenden Trübungsstreifen dieser Sternkatarakt (Abb. 15b) setzen sich bei 25 facher VergröBerung aus diffusem Staub und feinsten Punkten zusammen und sind, wie das schmale Büschel lehrt, in verschiedenen Rindentiefen verschieden stark a usgebildet. Einzelne Streifen durchsetzen die ganze Sohichtdicke der Vorderrinde, hinten die Kernvorderfläche, vorn die Kapsel erreichend. Mehrheitlich allerdings ist eine schmale Zone zwischen Kapsel und Abspaltungsstreifen klar. (Vordere und hintere Embryonalnaht intakt.) Vacuolen fehlen. An beiden Augen ist diese merkwürdige vordere Trübung in ganz ähnlicher Art ausgebildet. Ob sie angeborenen, stationären Charakter hat, oder aber erworben bzw. progredient ist, läßt sich nicht entscheiden. Patient gibt an, in den letzten Jahren eine Verschlechterung des Visus beobachtet zu haben.

Die Lage der vorderen Trübung innerhalb der sonst intakten Rinde, ohne Zusammenhang mit der Kapsel, läßt an eine erworbene Entstehung denken, während für die hintere Poltrübung die angeborene Natur wohl zweifellos ist.

\section{Katarakt im Bereiche des Ansatzes des physio- logisehen Hyaloidearestes, mit Ablatseh}

(Abb. 16 u. 17).

Am linken Auge des normalsichtigen, wegen Conjunctivitis behandelten 61 jährigen $G$. ist nasal vom Hinterpol an typischer Stelle ein gewöhnlicher Hyaloidearest vorhanden ( $\mathrm{Abb} .16$ ), der am unteren Ende der nasalen „Bogenlinie“" ansetzt. Die temporale Bogenlinie ist verdreifacht (Abb. 16), wobei die Einzellinien nicht glatt sind, sondern etwas unregelmäßige (kataraktöse?) Trübungsstreifen darstellen. Im Zentrum der Bogen, da, wo der Ansatzknäuel der Art. hyaloidea zu liegen pflegt, sitzt eine $0,3 \mathrm{~mm}$ messende,

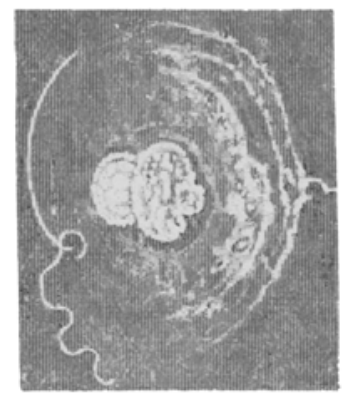

Abb. 16 . runde Kataraktscheibe von konzentrischer Zeichnung, ihr gegenüber vor dem Kernstreifen ein gröBerer, leicht gelappter Abklatsch (Abb. 17). Abb. 16 und 17 geben die beiden Trübungen bei schräger Aufsicht wieder. In Wirklichkeit liegen sie sagittal hintereinander. Bei Augenspiegeldurchleuchtung stellt die Gesamttrübung einen Punkt dar.

Es kamn wohl keinem Zufall unterliegen, daß diese typisch geformte Katarakt der Fintrittsstelle der Art. hyaloidea entspricht. Der Abklatsch zeigt, daß die Trübung alten, offenbar fötalen Datums und vielleicht auf eine Störung bei der Resorption der GefäBmembran zurückzuführen ist.

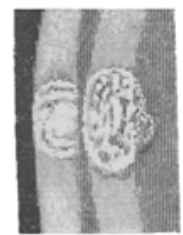

4bอ. 17. 
Hintere Polstare sind bisher wohl regelmäBig, sowohl topographisch als genetisch, mit Trübungen im Bereiche des Hyaloideaansatzes rermengt und verwechselt worden. Erst der von uns geführte klinische Nachweis des physiologischen Hyaloideaansatzes nasal vom Hinterpol gestattet die Scheidung von binteren Polstaren und Trübungen im Bereiche des Hyaloideaeintrittes.

\section{Besondere Ausprägung der ,, vorderen axialen Embryonalkatarakt"}

(Abb. 18, 19, 20).

Diese stationäre angeborene Starform, die ich in mehr oder minder ausgedehnter Form bei 20-25\% aller Augen fand und die nach Lage und Aussehen eine der typischsten und nach ihren Beziehungen zur vorderen Embryonalnaht eine der entwicklungsgeschichtlich interessantesten Linsenveränderungen darstellt, erreicht kaum jemals eine

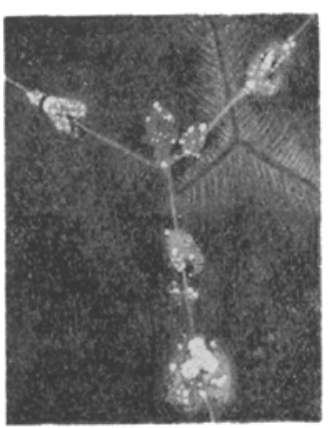

Abb, 18.

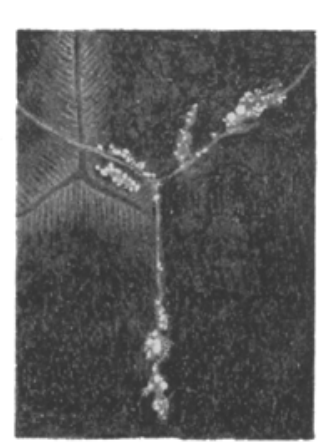

Abb. 19.

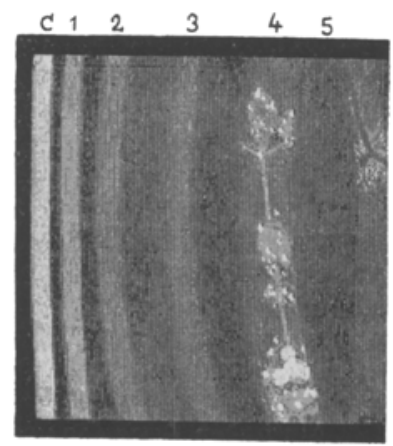

Abb. 20 .

Ausdehnung, welohe die Sehschärfe beeinträchtigt. Mit gewöhnlichen Methoden ist sie selten sichtbar (und natürlich nicht lokalisierbar), so daß sie als einer jener zahlreichen Befunde zu gelten hat, die dem Spaltlampenmikroskop vorbehalten blieben. Thre schneeweißen Punkte und Streifchen, die sich oft fingerig ordnen (wohl Faserin entsprechend) und öfters in einen reinweißen ,Glorienschein" gelagert sind, erzeugen in ihrem zierlichen Aufbau manchmal den Eindruck silbernen Filigranschmuckes. Mit keiner anderen Starform sind sie nach Aussehen und Lage zu verwechseln. Auch im Falle der Abb. 18 und 19 (rechtes und linkes Auge des 21 jährigen Frl. W.), wie in allen früher mitgeteilten, halten sie sich an die vordere Embryonalnaht oder doeh an ihre unmittelbare Nähe. Bei Frl. W. ist das Bild an beiden Augen ein fast äbereinstimmendes. Rechts, wo das $Y$ etwas schräg steht, sind die Trübungen ein wenig kräftiger als links. Beiderseits ist auch die hin tere (intalkte) Embryonalnaht mit ausstrahlender Faserung zu sehen (siehe Abb. 18 und 19). 
Zur Veranschaulichung der Diskontinuitätszonen dieses Falles gibt Abb. 20 die. Vertikalnaht des rechten Auges im verschmälerten Büschel wieder. C. Kpsel, 1 Abspaltungsfläche, 2, 3, 4 die darauffolgenden vorderen Diskontinuitätszonen, 5 zentrales Intervall. Die Länge der vorderen Embryonalstrablen ist folgende: vertikaler $R$. $1,2 \mathrm{~mm}, \mathrm{~L} 1,12 \mathrm{~mm}$, temp. ob. R. $0,72 \mathrm{~mm}, \mathrm{~L} .0,8 \mathrm{~mm}$, nasal ob. R. $0,8 \mathrm{~mm}$, L. (teils verdoppelt) $0,4 \mathrm{~mm}$. RS $=6 / 6 \mathrm{H} 0,5 \mathrm{LS}=6 / 6 \mathrm{H} 0,5$.

Über die mutmaßliche Genese dieses Stars habe ich mich an anderer Stelle ausgesprochen (Zeitschr. f. Augenheilk. 41, 125. 1918).

Sehichtstar mit nadeliörmigen Krystallen (Abb. 21-23).

Bei der $43 \frac{1}{2}$ jährigen Frau Fr. L. besteht von jeher Sehsehwäche und beiderseits ein fast symmetrisches Schichtstarbild. Beide Linsen sind leicht nach oben und innen verlagert (Abb. 21). Die Katarakt zeigt zwei konzentrische Haupttrübungszonen, eine dichtere zentrale und eine lockere periphere, letztere mit Radiärtrübungen (Abb. 21 Übersichtsbild, Abb. 22 ein Sektor bei 24 facher VergröBerung von vorne betrachtet). Der trübe zentrale Teil mißt $5,2 \mathrm{~mm}$, die ganze Trübung $8 \mathrm{~mm}$.

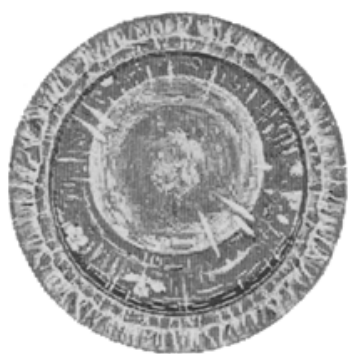

Abb. 21.

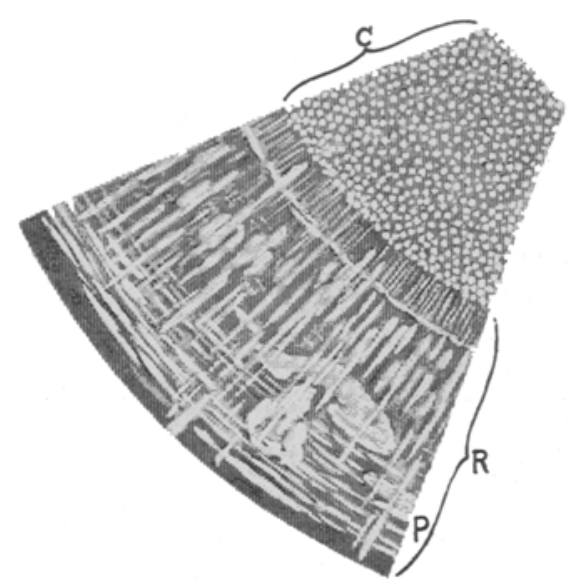

Abb. 22 .

Die stärkere (25fache) Vergrößerung ergibt den vollkommen differenten Aufbau dieser beiden Trübungspartien: Der zentrale Teil ist vorn von einer Schale weißer Punkte, welche alle ca. 40 Mikra Durchmesser haben, umhüllt (in $\mathrm{Abb} .22$ bei $C$, in $\mathrm{Abb} .23$, die einen optischen Schnitt im dủnnen Büschel dar. stellt, Streifen 4). Im hinteren Teil dieses Kerns konnte diese Punktzone (vielleicht wegen ungenügender Durchsichtigkeit der Linse) nicht festgestellt werden. Die periphere, die vordere "Punktschale" umbüllende Trübungspartie (Abb. 23, Zone 3, Abb. 22, Zone $R$ ) zeigt sowohl radiäre als konzentrische Streifung. Die konzentrische Streifung findet sich nur am Äquator (Abb. $22 P$ ), an der Grenze gegen die klare Rinde. Unter der Punktschale sitzt eine Zone von farbig glänzenden Nadeln (Abb. 23, Zone 5 und 6), die, oft zu Büscheln geordnet, bald mehr radiär, bald mebr konzentrisch verlaufen. Es handelt sich morphologiseh um dieselben Nadeln, die ich in Abb. 204 und 205 des Atlas der Spaltlampenmikroskopie wiedergab. Sie stellen offenbar eine sekundäre, im Laufe der Jahre ent.

1) Im Falle der Abb 205 waren sie mit rhombischen Tafeln vom Typus des Cholesterins kombiniert. Uber die mutmafliche Natur dieser Nadeln vergl. den Text zu den Abb. 35 und 30 (Spießkatarakt). 
standene Veränderung dar. Zwischen die vordere der Nadelzonen (5) eingestreut ist eine lockere Reihe nunder weiBer Trübungsflecken, die etwa den doppelten Durchmesser der Schalenpunkte besitzen. Der zentrale Teil der Linse ist trübungstrei. In Abb. 23 ist $C$ die Vorderkapsel, 1 der Abspaltungsstreifen, 2 eine Zone leichter Veränderung, 3 die äußere Trübungsschale (Zone der radiären und konzentrischen Trübungen). Auf diese Zone folgt ein dunkles (lucides) Intervall, daran

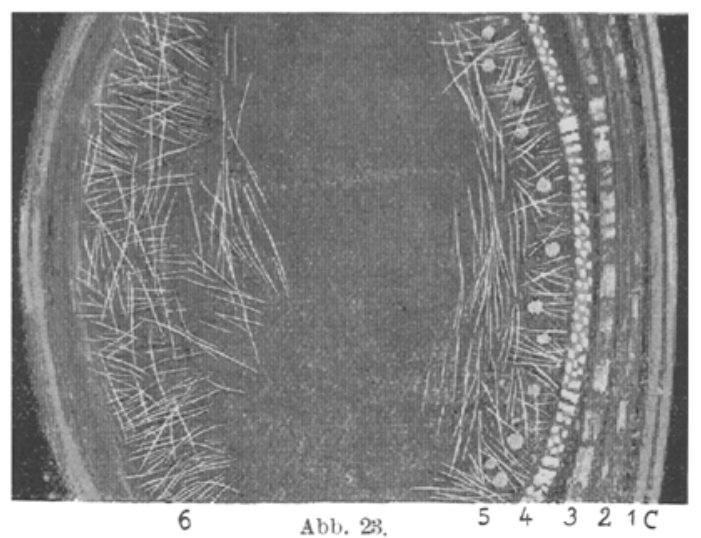

schlieBt sich die Schale der weißen Punktrübungen (4), 5 and 6 sind die Zonen der Nadeln. RS $=6 / 26(-8,0 \mathrm{D})$, LS idem.

Die Katarakt wurde beiderseits discidiert und ohne Komplikation extrahiert.

\section{Schichtstar mit besonderer Ausprägung des Nahtsystems (Nahttypus)} (Fig. 24 schwach vergr).

Diese Fom des Schichtstars zeichnet sich durch glatte Begrenzung, auch des Äquators, durch die feine staubförmige Struktur der Trübungs-

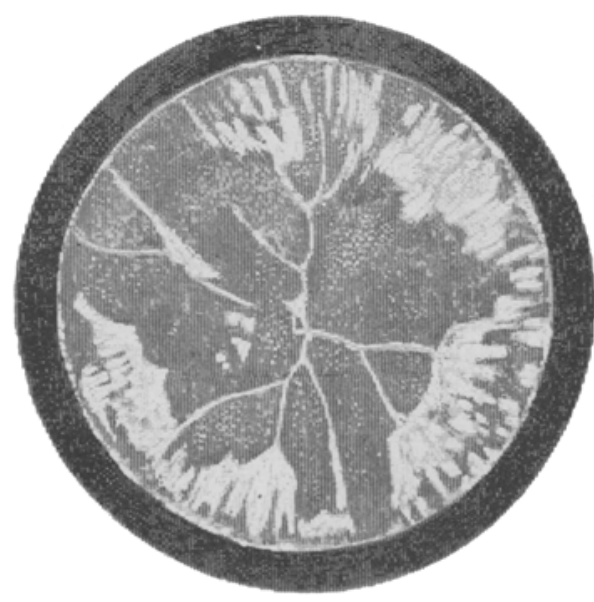

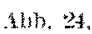
oberfläche beí relativ klarem Kern und durch auffällige lineare Trübung der Nähte aus, welche weiBe Linien im Bereiche der Trübungsoberfläche darstellen.

An boiden Augen der 23jährigen Krankenschwester Gir. B. sind sowohl die vorderen als die hinteren Nähte der Staroberfläche als weiße Tinien sichtbar. Peripher der Nahtenden und zwischen denselben beteiligen sich ferner einige Faserzinge als breite trübe Radiärstreifen. Das zentrale Sehvermögen ist relativ wenig beeinträchtigt: $\mathrm{BS}=6 / 200$ Glhn, LS $=9 / 12$ Glbn. 
Es kann diese Schichtstarform als Nahtty pus einem Spaltentypus (Abb. 235 des Atlas der Spaltlampenmikroskopie) gegenübergestellt werden. Abb. 24 zeigt die hintere, Abb. 24a (sch wächer vergr.) die vordere Trübungsschale des rechten Auges, Abb. $24 \mathrm{~b}$ die hintere, Abb. $24 \mathrm{c}$ die vordere Schale des linken Auges. Macht man die Annahme, daß die trüben Nahtsysteme bzw. die Trübungsschale, der sie angehören, zur Zeit des Zerfalls superfiziell lagen, so ergibt sich als Zeitpunkt der Kataraktbildung etwa das erste bis zweite Lebensjahr (vgl. über die Entwicklung der Nahtsysteme Abb. 105-124 des Atlas der Spaltlampenmikroskopie).

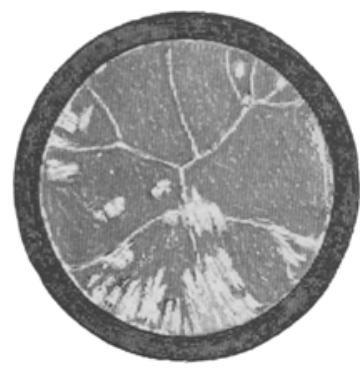

Abb. 24a.

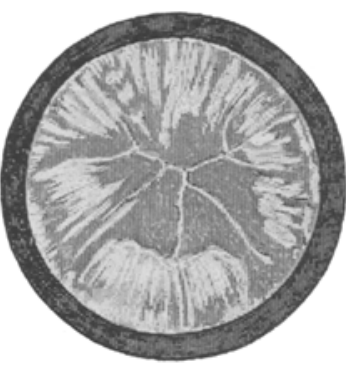

Ahb. 24 b.

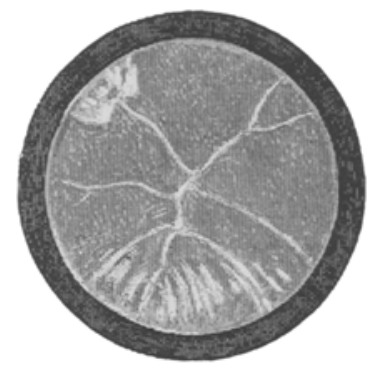

Abb. $24 \mathrm{c}$

Aber auch ohne die genannte Annahme ergibt unser Befund, da $ß$ die Trübung Linsenabschnitte betrifft, welche ante partum noch nicht vorhanden waren, daß also diese Trübungen zur Zeit der Geburt noch nicht existieren konnten. Derartige Überlegungen zeigen, von welcher theoretischen und praktischen Wichtigkeit die Kenntnis der Nahtsysteme sein kann, über deren Entwicklung bisher wenig bekannt war.

\section{Schichtetar mit zweifacher Punktzone und Reiterchenhülle, im Schnitt} des schmalen Büschels (Abb. 25-27).

Bei dem 23jährigen, von jeher sehschwachen B. E. zeigt der Schichtstar den Bau der Abb. 25 (Sagittalschnitt). Nähte sind nicht zu erkennen. Die sehr zahlreichen

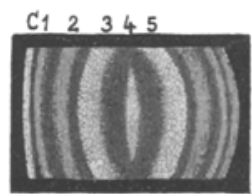

Abb. 25.

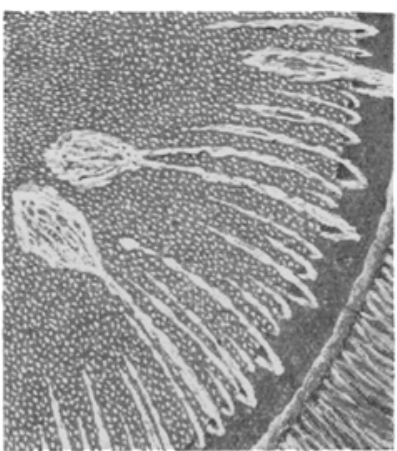

Abb. 26 ,

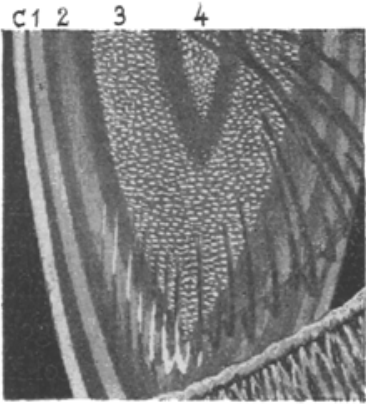

Abb. 27. 
Reiterchen sind von zweifachem Typus: längere, den Äquator stärker überragende Formen wechseln ziemlich regelmäßig mit kürzern, dem Äquator enger anliegenden (Abb. 26). Die längere Form ist endwärts gelegentlich schaufelartig verbreitert. Spaltenbildung oder Nahtzeichnung fehlen. Das verschmälerte Büsschel (Abb. 27) zeigt Abspaltungszone 1, Alterskernzone 2 mit den Trübungshaken, periphere Punktzone 3 und zentrale Punktzone 4, zwischen beiden Punktzonen ein lucides Intervall. Die schwarzen Bogenlinien sind die Schlagschatten von Reiterchen. Abb. 25 gibt ein Úbersichtsbild über den Linsenaufbau, 3, 4 und 5 sind die Trübungszonen. $\mathrm{RS}=6 / 36(-6,0 \mathrm{D})$, links Aphakie seit 8 Jahren.

Im Vorstehenden sind nur einige wichtigere Typen des Schichtstars wiedergegeben, wie sie im Spaltampenmikroskop erscheinen. Es ist durch die Gullstrandsche Spaltlampe, speziell durch die Anwendung des verschmälerten Büschels, die Möglichkeit gescbaffen, lucide und trübe Zonen innerhalb des Stars zu erkennen und gegeneinander abzugrenzen.

Ätiologisch ist der Schichtstar heute noch unklar. Klinisch ist sowohl prä-als postnatale Genese wabrsckeinlich gemacht. Daß letztere vorkommt, lehren unsere Nahtbefunde (vgl. Text zu Abb. 24). Künftige exakte Ermittlung des Stardurchmessers einerseits und des normalen Linsendurchmessers der verschiedenen fötalen und postfötalen Lebensabschnitte andererseits werden in dieser Hinsicht vielleicht weiter aufklären, insofern, als eine selkundäre Volumenzunahme des scharf umschriebenen Kataraktbezirks nicht anzunchmen ist.

Unsere Spaltlampenbefunde bei Schichtstar scheinen, so sehr sie auch weitere Mannigfaltigkeiten des Starbildes aufdecken, die herrsclende Auffassung zu stützen, wach welcher der Aufbau aus differenten, konzentrischen Trübungsschalen in manchen Fällen auf eine exogene (vielleicht chemisch-nutritive) Noxe hinweist, die evtl. zu verschiedenen Zeitabschnitten und in verschiedener Art zur Wirkung gelangt. Dickere Trübungsschalen (vgl z, B. Abb. 27, Zone 3) würden auf eine längere, dünnere auf eine kürzere Dauer der schädigenden Wirkung hinweisen. DaB jedoch die Ursache nicht immer eine so ejnfache, gewissermaßen mechanistische sein kann, lehren uns auch hier die hereditären Fälle. Familiäres Auftreten bzw. Heredität sind in einer Reihe von Sohichtstaren sicher nachgewiesen, in anderen nicht auszuschließen. Von Bedeutung sind in dieser Richtung die Forschungen A. v. Szilys, der bei idiokinetischen, $d . h$, hereditaren Starformen gewisser Tiere die pathologische Persistenz von Zellen nachwies, die, statt resorbiert zu werden, zerfallen und zu Kataraktbildung AnlaB geben. Im Gegensatz dazu verursachen äußere Noxen direkten Zellzerfall (parakinetische Genese). Nicht ausgeschlossen ist, daß die v. Szilyschen Befunde auch fü den menschlichen Schichtstar (wie auch für die weiterhin zu besprechenden Formen von Katarakt des Embryonalkerns) Be- 
deutung haben. (Die Einzelbefunde v. Szilys sind in der Literatur noch nicht niedergelegt. Vgl. Ber. d. Ophthalmol. Ges. Heidelberg 1910 und 1918).

Bisher schien der Umstand, daß uns das Verständnis für die hereditären Vorgänge fehlte, gelegentlich ein Grund gewesen zu sein, sie bei der Aufstellung von Hypothesen zu vernachlässigen.

Daß nahe Beziehungen zwischen Polstar und Schichtstar bestehen, lehrt die häufige Kombination beider Formen. Vielleicht wird das Auftreten der Poltrübung durch die besondere Empfindlichkeit des vorderen und hinteren Nahtzentrums, wie sie z. B. in der Cataracta complicata zutage tritt, begünstigt, vielleicht auch entscheidet über Mitbeteiligung oder Freibleiben der Pole lediglich die vererbte Anlage.

Zentralstar mit Verbindungsstreifen nach der Vorderkapsel (Abb. 28-30).

Abb. 28 (schwache Vergrößerung) zeigt den Star an dem linken, milkrophthalmischen Auge des 10 jährigen Lï.. Jakob. Horizontaler Hornhautdurch-

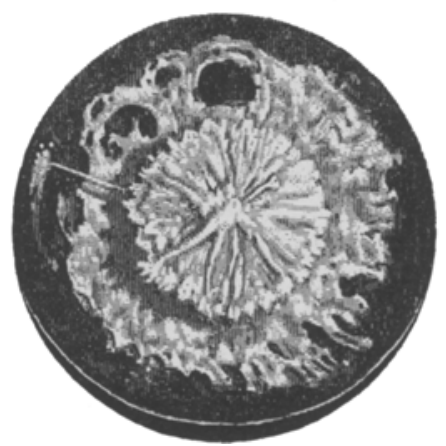

Abb. 28.

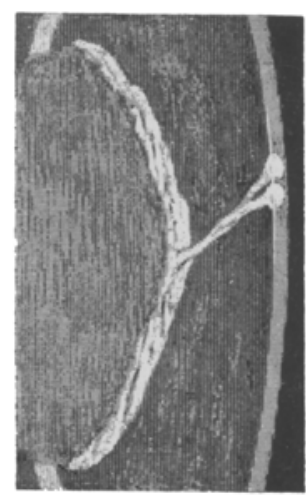

Abb. 29.

messer rechts $11^{1 / 2} \mathrm{~mm}$, links $9^{1 / 4} \mathrm{~mm}$ (rechtes Auge normal). Bei Mydriasis von $7 \mathrm{~mm}$ zeigt sich der linke untere Linsenrand (Abb. 28). Linse somit etwas nach oben verlagert. Die Trübung (Abb. 28) setzt sich aus einem intensiveren zentralen Kern und einer dicht dahinter liegenden, z. T. durchlöcherten, größeren, nach vorn konkaven Schalentrübung zusammen. Letztere hat im Durchschnitt $5 \mathrm{~mm}$ Frontaldurchmesser, der ihr aufliegende dichte, Radiärfirsten tragende Kern 2,5-3 mm. Dieser Kern ist leicht zackig begrenzt. Noch unregelmäßiger ist die Begrenzung der größeren Trübungsscheibe (Abb. 28). Z. T. ist sie durchlöchert (größtes Loch oben von $0,8 \mathrm{~mm}$ Durchmesser), z.T. ziehen breite Trübungszüge zum hypothetischen Trübungsäquator

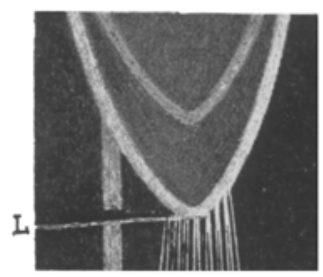

Abb. 30. (z. B. temporal-unten). Die vordere Trubung liegt. der hinteren nur in den axialen Partien auf, so daß Spindelform entsteht. Ein verbindender Trübungs. zweig geht vom nasalen Rande der vorderen zu dem der hinteren Trübungsscheibe. 
Abb. 29 (25fache Vergrößerung) gibt einen isolierten Trübungsstrang wieder, der die sonst fast klare vordere Rinde schräg durchsetzt, indem er von der vorderen Trübungsscheibe, etwas oberhalb deren vorderem Pol, ausgeht, schräg nach vorn oben zieht und, nach Gabelung, unter stempelartiger Verbreiterung der Enden hinter der Vorderkapsel haltmacht (Abb. 29). Er erreicht, was betont sei, diese letztere nicht ganz.

Unter der Vorderkapsel eine Menge feiner Punkttrübungen. Auf der Kapsel Sternchenpigment. Abb. 30 illustriert den Sagittalschnitt des unteren Linsenrandes. Die Abspaltungsfläche entfernt sich hier, wie dio Abbildung zeigt, beträchtlich vom Aquator (normales Verhalten). Außer der am letzteren sichtbaren Zonulafasern sieht man einen hinteren vertikalen Strang, dessen Natur nicht klar ist (Zonulastrang oder Glaskörper?). Die horizontale dunkle Linie $L$, die diesen Strang zu durchschneiden scheint, kommt durch Lichtbrechurg am Äquator (scheinbare Schattenbildung) zustande.

Epikrise: Es handelt sich hiex um einen einseitigen Zentralstar von Spindelform, der vielleicht für den Mikrophthalmus des betreffenden Auges verantwortlich zu machen ist. Gelang doch Wessely am Kaninchenauge der Nachweis, dal das Wachstum des Bulbus nach Zerstörung der Linse zurückbleibt.

Auf eine Störung bei der Abschnürung des Linsenbläschens im Simne v. Hess" könnten die zentrale Trübung and der nach rom gerichtete Trubungsstrang hinweisen. Immerhin ist zu beachten, daß der genannte Strang (wie auch in einem ähnlichen Falle von Vossius 1. c.) extrapolar gerichtet ist. - Die rollkommene Kerntrübung unseres Falles würde bei einer derartigen Annahme die weitere Hypothese voraussetzen, daß zufolge der Störung der Abschnürung der Kern sich zwar mehr oder weniger normal entwickelte (aus zerfallenen Fasem konnte er sich nicht wohl bilden), sekundär dann der Totaltrübung verfiel. Näker scheint uns die umgekehrte Annahme zu liegen, daß der Kern sich bereits normal geformt hatte, als die Ursache der Trübung und damit der Zerfall sich geltend machten.

Morphologisch erinnert unser Fall an den von v.Hess $(1, \mathrm{c}$.) in Abb. 33 wiedergegebenen. Doch konnten wir eine Kernverlagerung nach rückwärts nicht feststellen.

\section{Linsenförmige zentrale stanb und punktörmige Fmbryonalkatarakt} (Abb. 31).

Die Katarakt der Abb, 31 (55jährige Frau Hi., linkes Ange, rechts Abulbie, 25fache Vergrößerung) und ihr ähnliche Trübungsformen des Embryonalkerns sind bisher bei ihrer Kleinheit und geringen Dichte sicher oft übersehen worden. In der Literatur sind, soviel ich sehe, solche Starformen nicht beschrieben. Und doch dürften sie nach unseren Befunden nicht zu den Seltenheiten gehören.

Auch im vorliegenden Fall war die Trübung nur bei Durchleuchtung mit Lupenspiegel wahrnehmbar, während das Spaltlampenmilkroskop zwischen vorderer und hinterer Embryonalnaht die lebhafte Tribung der Abb. 31 anfdeckte. 
Vorderer und hinterer Pol der etwa halb so dicken als breiten, linsenförmigen Trübung finden sich in wohl erkennbarer Distanz von jenen Nähten. Die Trübung setzt sich aus einem zentralen $0,72 \mathrm{~mm}$ messenden Kern und einem peripheren Ring von $1,04 \mathrm{~mm}$ Lumen zusammen. Beide Abschnitte sind äquatorial scharf begrenzt, indem hier eine Verdichtung der Trübung zu einer Art Grenzlinie besteht, und setzen sich aus weißen, hier und da konfluenten Punkten zusammen. Die Punkte sind unmeBbar fein, doch ist häufig ein lichter Hof um dieselben erkennbar. Die weiße Farbe und der lichte Hof zeichnen angeborene Trübungen des Embryonalkerns, also Linse ntrübungen ältesten Datums, nach unseren Beobachtungen häufig aus, Trübungen somit, deren Genese wahrscheinlich in die ersten Embryonalmonate zu verlegen ist. Zentral zeigen die Punkte des vorliegenden Falles radiäre Anordnung. Größere verwaschene Punktgruppen messen bis zu $0,1 \mathrm{~mm}$. Peripher vom äußeren Ringe, in einer

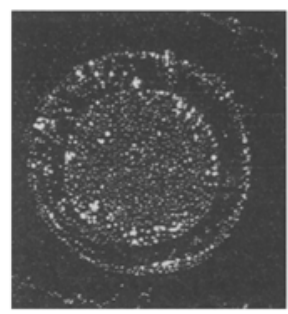

Abb. 31. Distanz von ca. $0,3 \mathrm{~mm}$ vom letzteren, sieht man Andeutungen eines dritten konzentrischen Trübungsringes (in der Abbildung temporal oben und unten innen). $\mathrm{LS}=\% / 6$ H 1,25 .

Haben wir diese, nur etwa $1 \mathrm{~mm}$ messende Katarakt zu den Schichtstaren zu rechnen? Der konzentrische Aufbau würde dafür sprechen. Weniger mißverständlich ist es, sie als "zentrale Embryonalkatarakt" zu rubrizieren.

\section{Linsenförmige staub- und punktförmige Embryonalkatarakt im Bereiche der vorderen Embryonalnaht (Abb. 32.)}

Die linsenförmige Trübung, deren Äquatorialdurchmesser 1,05 mm ist, sitzt nicht genau im Linsenzentrum. Bei Verwendung des schmalen Büschels ist schon makroskopisch erkennbar, daB die Trübung ein weniges vor dem Zentrum liegt Sie erfullt nämlich die Gegend des zentralen Intervalls und der vorderen Embryonalnaht. Letztere ist nicht zu sehen, während die unmittelbar hinter der Trübung gelegene hintere embryonale Naht exkennbar und frei ist. Die äquatoriale Begrenzung der Katarakt ist, im Gegensatz zur vorigen Form, kei ne linea re, im Gegenteil verlieren sich die Punkte da und dort allmählich in die Umgebung. Auch läßt die Trübung. keine konzentrische Struktur erkennen. Immerhin ist der Äquator auch hier angenähert kreisförmig. Die Punkte sind glänzend weiße Plättchen verschiedener Größe. Die gröBten messen ca. $0,04 \mathrm{~mm}$, die kleinsten sind staubförmig. An einer

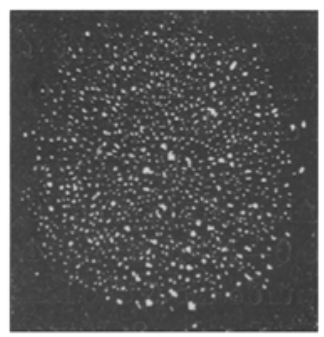

Abb. 92 . Stelle blinkt ein Kryställchen (Cholesterin?). Die größten Punkte lassen eckige bis rundlich-eckige Form erkennen. Besonders zentral ist eine radiäre Anordnung der Püktchen unverkennbar. Der sagittale Dickendurchmesser der Trübung beträgt schätzungsweise etwas mehr als die Hälfte des äquatorialen. Eine zweite, unbedeutende Trübungszone liegt in einer Diskontinuitätsfläche, die der Lage nach etwa der Alterskernzone entspricht. Es sind ca. 15 auf den Kernumfang verteilte Hakentriibungen, die nach Form und Ausdehnung den Reiterchen der Abb. 26 entsprechen. Z. T. stehen sie in Gruppen, z. T. sind sie vereinzelt. Auch zwei oder drei Keulentrübungen, wie sie die Coronartakarakt 
auszeichnen, sind in Kernäquator vorhanden. Im übrigen Bereich der genannten Diskontinuitätszone vereinzelte kleine, mehr oder weniger unregelmäßige Punkte und Flecken. (12 jähriger Knabe M., RS $=0,8 \mathrm{H}$ 1,0, links Abulbie.)

\title{
Staub- und punktförmige vordere Embryonalkatarakt von Ringiorm
}

\author{
(Abb. 33).
}

Bei der 32 jährigen Frau L. ist die vordere Embryonalnaht (Abb. 33) beiderseits ganz besonders deutlich und zeigt leichten Seidenglanz. Der vertikale Schenkel

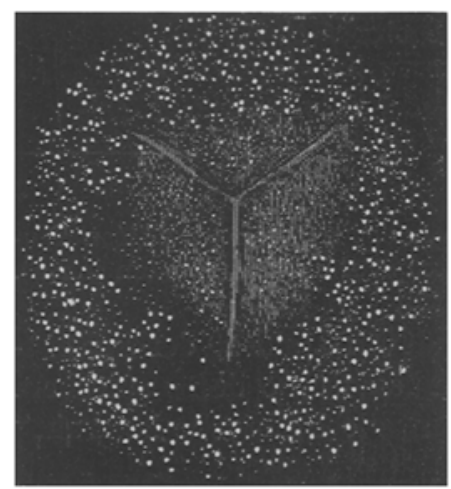

Abb. 383. mißt am linken Auge $1 \mathrm{~mm}$, der nasale obere 0,6 , der temporale obere $0,5 \mathrm{~mm}$. (Rechts sind die Maße und die übrigen Verhältnisse ganz ähliche.) In der nachsten Umgebung dieser vorderen Embryonalnaht, neben und hinter derselben einige schwache Staub- und Punkttrübungen. In der weiteren Umgebung ein Kranz von weißen, gröberen und feineren, meist rundlichen Punkten, welche häufig wieder jenen zarten lichten Hof zeigen, der die embryonalen Trübungen oft auszeichnet. Gesamtdurchmesser dieses gröBeren Trübungs. ringes $=2,7 \mathrm{~mm}$. Frontale Ringbreite durch sohnittlich $0,6 \mathrm{~mm}$. Wieder ist die Begrenzung des Trübungsringes keine lineare, son. dern eine mehr allmähliche.

Die hier mitgeteilten drei Formen von Punktkatarakt des Embryonalkerns reihen sich an die im Atlas der Spaltlampenmikroskopie in Abb. 235c und d wiedergegebene, ,Cataracta centralis pulverulenta" an. Sie haben das Gemeinsame, daß sie die zentrale älteste Linsenpartie betreffen, einen bis höchstens $3 \mathrm{~mm}$ messen ${ }^{1}$ ) und aus weißen Punkten und Staubtrübungen sich zusammensetzen, die nicht dicht genug stehen, um Undurchsichtigkeit zu bewirken. Die Sehschärfe ist daher in diesen Fällen nicht nennenswert herabgesetzt.

Berücksichtigen wir, daß das Linsenbläschen nach Vollendung der Abschnürung ca. $0,4 \mathrm{~mm}$, in der 6. Woche ca. $0,5 \mathrm{~mm}$, im 3. Monat $0,9-1,4 \mathrm{~mm}$, im 4. gegen $2 \mathrm{~mm}$ Äquatorialdurchmesser aufweist, so würde die trübe Linsenpartie der A u s dehnung nach etwa der ersten Hälfte des 3. Monats, der Zeit, da sich die Pupillarmembran zu bilden beginnt, also die Ernährungsverhältnisse der Linse eine Anderung erfahren, entsprechen. Dabei wäre freilich die Annahme vorausgesetzt, daß der zentrale Linsenabschnitt im Laufe des Lebens sich nicht wesentlich verkleinert, und es ist ferner die durch die Hornhaut bedingte unbedeutende VergröBerung bei der Messung vernachlässigt.

1) ฯ. Hess beobachtete einen vielleicht hierhergehörigen Schichtstar von $2 \mathrm{~mm}(\mathrm{l} . \mathrm{e})$.) 
Wollten wir somit die Hypothese als zulässig erklären, die genannten Starformen entständen durch irgendeine Störung in der Ernährung, so wäre es naheliegend, die letztere in den Zeitabschnitt zu verlegen, in der die Ernährung der jungen Linse eine Umgestaltung erfährt, also etwa in den dritten Fötalmonat.

\section{Ringförmige (roßkümmelähnliche), strahlig geordnete Trübungen der vorderen Alterskernzone (Abb. $34 \mathrm{a}$ und $\mathrm{b}$ ).}

Linkes Auge des 10 jährigen I. O. (rechtes Auge normal). Abb. 34a Übersichtsbild, $\mathrm{Abb}$. $34 \mathrm{~b}$ Darstellung im breiten Büschel. $O=$ Chagrin der Linsenoberfläche, mit dunklen Nahtlinien $N, D=$ Diskontinuitätszone, in der die

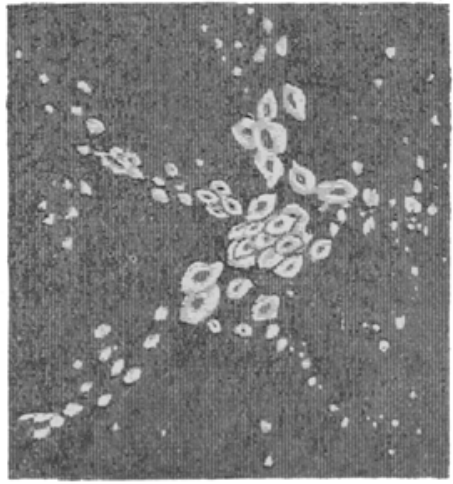

Abb. 34 a.

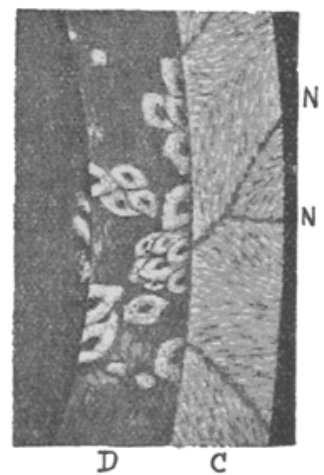

Abb. 34 b.

sämtlichen Trübungen liegen. Man beachte die gröberen, länglich-ringförmigen und die kleineren ovalen Trübungen. Alle sind flächenhaft. $\mathrm{d}$. $\mathrm{h}$. sie breiten sich in ein und derselben Diskontinuitätsfläche aus.

Ringförmige, und zwar rundliche Trübungen flächenhafter Art findet man gelegentlich bei Coronarkatarakt. Aber sie bilden dort die untergeordnete Trübungsform. Im vorliegenden Falle zeigen sämtliche gröbere Trübungen Ringform und sind auBerdem in radiärer Richtung in die Länge gezogen. Eine Beziehung zum Nahtsystem gibt sich dadurch kund, daß die Trübungen axial am zahlreichsten und dichtesten sind und in radiären Reihen peripherwärts sich ausbreiten, dort allmählich in Punkte sich verlierend (Abb. 34a). Die Farbe im auffallenden Licht ist weißgelblich.

\section{Spießkatarakt.}

Besser als jede Beschreibung geben die Abb. 35 und 36, rechte und linke Linse des 9 jährigen R. G., 24 fache Linearvergrößerung, ein Bild von der abenteuerlichen Form dieses Stars. In den mittleren Linsenpartien sitzen die oft an Insekten erinnernden, bald wurstartig geringelten, bald in bunt- 
farbigen Nadeln starrenden Trübungsmassen, deren Verlaufsrichtung von dem ana. tomischen Bau der Linse in keiner Abhängigkeit za sein scheint.

Die buntfarbig schillexnden, gelegentlich millimeterlangen Nadeln sind häufig zu Bündeln geordnet, verhalten sich also ähnlich wie Tyrosinkrystalle. In anderen

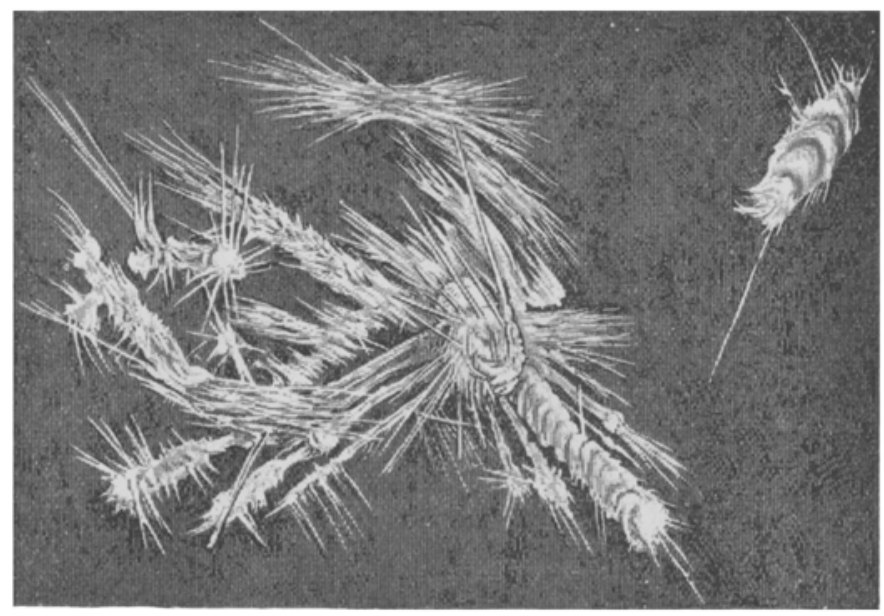

Abb. 35.

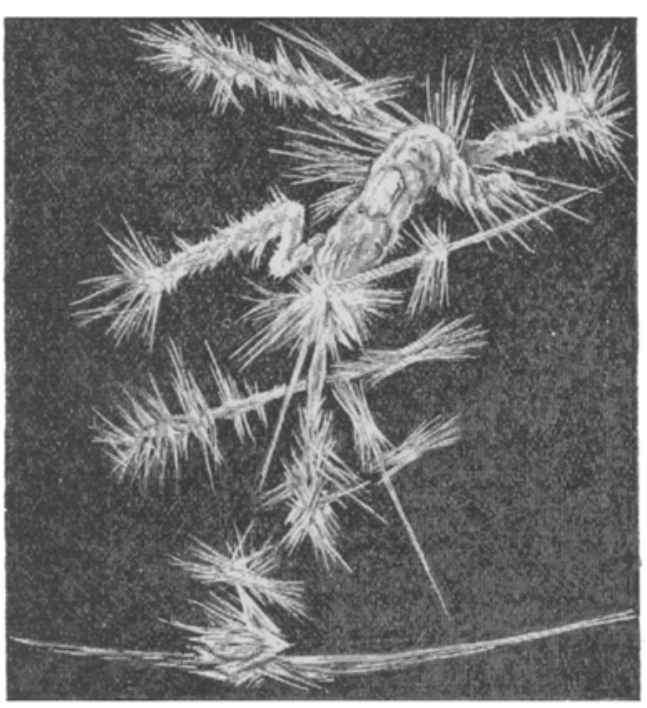

Abb. $366_{n}$

Fällen strahlen sie nach den verschiedensten Richtungen auseinander, selten jedoch durcheinander.

Ähnliche,"aber kürzere und zu einer Schicht gelagerte $\mathrm{Na}$ deln haben wir in Abb. 23 kennengelernt, und als Vor. läufer des traumatischen Totalstars habe ich sie in Abb. 204 und Abb. 205 des Atlas der Spaltlampenmikroskopie abgebildet. Hier waren sie mit typischen rhombisehen Cholesterintafeln kombiniert. In jenemi Falle von traumatischem Star konnte man daran denken, daB die schlanken Nadeln vielleicht veränderte Linsenfasern darstellen. Im Falle von Abb.35 und 36 ist dies nicht mehr möglich. Hier verlaufen die Bündel derart in den verschiedensten Richtungen, daß eher der Eindruck erweckt wird, sie seien das Produkt einer Auskrystallisation innerbalb einer ungeformten Masse.

Der 9 jährige, im übrigen gesunde Knabe hat eine Sehsohärfe von rechts = $6 / 24$ Glbn, links $=6 / 24$ Glbn. 
Die Katarakt bietet ein so auffälliges Bild, daß man erwarten sollte, sie sei irgendwo schon beschrieben worden. Ich konnte aber in der Literatur hierüber nicht Gewisses finden.

Vielleicht sind folgende Starformen englischer Beobachter mit der unsrigen wenigstens verwandt:

In der englischen Literatur existiert eine ,koralliforme Katarakt". Gunn (Transact. of the ophthalmol. soc. of the kingdom 15; 1895) berichtet über eine solche ,eigentümliche coralliforme Katarakt mit (Cholesterin?-) Krystallen", und gibt auf Taf. IV, Abb. 3, eine Abbildung wieder. Aus der letzteren geht allerdings nicht hervor, daß es sich um unsere Starform handelt. Bei fokaler Beleuchtung sah man beiderseits rundliche und längliche Trübungen von grauer und weißer Farbe in Gruppen gegen das Linsenzentrum angeordnet. Das Ganze glich einer Rosette. Die länglichen Trübungen stellten konische Röhren dar, alle zeigten am vorderen Ende weiße Kreise oder Ovale. Daneben viele zart farbenschillernde Krystalle in den klaren Rindenpartien.

Fisher (ibid. 25, 90; 1905) beschreibt „,koralliforme Veränderungen“ bei einer 47 jährigen Frau aus einer Starfamilie: Die befallenen Rindenpartien waren ganz korallenähnlich, Trübungen z. T. stark glänzend. Eine axiale Spindel verband vordere und hintere Rindentrübungen. Im Laufe von vier Jahren sank der Visus von einem Drittel auf weniger als ein Zehntel. Die Katarakt war also progredient. Die erwähnte Spindel hatte ursprünglich nicht bestanden.

Auch Nettleship beschreibt aus einer Starfamilie koralliforme Cataract. 28 von 100 Mitgliedern dieser Familie waren starbehaftet ${ }^{1}$ ).

Endlich stellte 1906 Stephenson (ibid. 26, 119) einen 36 jährigen Patienten vor mit beiderseitiger optischer Iridektomie wegen ,, lamellärer

1) Nettleship (on Heredity in the various Forms of Cataract, ophth. Hosp. Rep. Vol. XVI. 1906. S. 179) spricht allerdings von Spindelstaren, S. 219: "Die Trübungen hatten die Form von dichten, stumpfendigenden Fortsätzen, die schräg nach vorn und außen ausstrahlen (d. h. gegen den Äquatos), ohne die Kapsel zu erreichen. Jeder Sproß der Fortsetzung endigt in eine Art trompetenähnlicher Ausweitung oder ,Mund“ einer Koralle. Knies hat sie verglichen mit den ,Flügeln einer Windmühle". (Mit den Spindelstaren Knies" hat unsere Cataract sicher nichts zu tun. Ref.). - „Cholesterin kommt bei der koralliformen Cataract häufig vor", S. 220: „Wine allgemeine Ưbersicht über den Stammbaum zeigt, daß die Übertragung der Cataract stets kontinuierlich ist, d. h. jedes cataractöse Kind hat einen cataractösen Elter, ferner, daß die Cataractösen in entschiedener Mehrheit männlich waren $(20 \delta, 11 Q) . *$ - In einem Falle Langenhan's (Zeitschr. f. Augenheilk. 21, 514. 1909) bestand ebenfalls korallenähnliche Form. Aber auch sein Fall scheint erheblich von dem unsrigen abzuweichen. - Das Spaltlampenmikroskop wird die Morphologie dieser Starformen besser umgrenzen helfen. Auch die genaueste Beschreibung vermag eine gute Abbildung nicht zu ersetzen. 
Katarakt" (Schichtstar). Die „coralliforme Katarakt" bestand beiderseits aus dünnen Röhrcken in einer trüben Masse, von denen einige vom Äquator, andere von der Vorderfläche der Trübung entsprangen. „Das Ganze gleicht einem Korallenstück zu sehr, als daß man es leicht. überseken könnte." Herbert Fisher hielt diesen Fall nur für eine besondere Form von Schichtstar, mit coralliformen einzelnen Partien, im Gegensatz zu den früher mitgeteilten hereditären und progredienten Fällen.

Aus dieser Darstellung und aus der Fisherschen Abbildung ergibt sich somit keineswegs eine Utbereinstimmung mit unserer Spießkatarakt, so daß unsere Beobachtung wohl bis jetzt isoliert dasteht.

Von besonderem theoretiscten Interesse ist in unserem Falle die Tatsache, daß innerkalb anseleinend normaler klarer Linsensubstanz eine Trübung sich bildet, die morplologisch vom Aufbau der Linse unabhängig zu sein sckeint und deren massenhafte krystallinische Ansläufer sich gleichsam in amorpher Masse ausgeschieden haben ${ }^{1}$ ).

1) Über weitere Eigentümlichkeiten der Spießcataract vgl. die Fortsetzung zu diesem Abschnitte. Herr Prof. S piro, Vorsteher des physiologisch-chemischen Instituts unserer Universität, hatte die Freundlichkeit die eine der von mir extrahierten Linsen des Knaben R. G. (Extraktion nach Discission, kein Glaskörperverlust, glatte Heilung) zu untersuchen. Er glaubte zunächst, unsere Vermutung, daß die Nadeln aus Tyrosin bestehen, bestätigen zu können. Eine nochmalige Prüfung machte jedoch Zystein wahrscheinlicher. Auch Cholesterin läßt sich nach Prof. Spiro, trotz der Nadelform, nicht sicher ansschließen. 